\title{
Article
}

\section{Anti-TRBC1 Antibody-Based Flow Cytometric Detection of T-Cell Clonality: Standardization of Sample Preparation and Diagnostic Implementation}

\author{
Noemí Muñoz-García 1,2 (D), Margarida Lima ${ }^{3,4}$, Neus Villamor ${ }^{2,5}$, F. Javier Morán-Plata ${ }^{1,2}$, Susana Barrena ${ }^{1,2}$, \\ Sheila Mateos ${ }^{1,2}$, Carolina Caldas ${ }^{1,2}$, Ana Balanzategui ${ }^{2,6}$, Miguel Alcoceba ${ }^{2,6} \mathbb{D}$, Alejandro Domínguez ${ }^{7}$, \\ Fabio Gómez ${ }^{7}$, Anton W. Langerak ${ }^{8} \mathbb{D}$, Jacques J. M. van Dongen ${ }^{9} \mathbb{D}$, Alberto Orfao ${ }^{1,2,+}+^{\mathbb{D}}$ \\ and Julia Almeida $1,2, *,+(D)$
}

check for updates

Citation: Muñoz-García, N.;

Lima, M.; Villamor, N.;

Morán-Plata, F.J.; Barrena, S.; Mateos,

S.; Caldas, C.; Balanzategui, A.;

Alcoceba, M.; Domínguez, A.; et al.

Anti-TRBC1 Antibody-Based Flow

Cytometric Detection of T-Cell

Clonality: Standardization of Sample

Preparation and Diagnostic

Implementation. Cancers 2021, 13,

4379. https://doi.org/10.3390/

cancers 13174379

Academic Editor: Aldo M. Roccaro

Received: 14 July 2021

Accepted: 23 August 2021

Published: 30 August 2021

Publisher's Note: MDPI stays neutral with regard to jurisdictional claims in published maps and institutional affiliations.

Copyright: (c) 2021 by the authors. Licensee MDPI, Basel, Switzerland. This article is an open access article distributed under the terms and conditions of the Creative Commons Attribution (CC BY) license (https:// creativecommons.org/licenses/by/ $4.0 /)$.
1 Translational and Clinical Research Program, Centro de Investigación del Cáncer and IBMCC (CSIC-University of Salamanca), Cytometry Service, NUCLEUS, Department of Medicine, University of Salamanca (USAL) and Institute of Biomedical Research of Salamanca (IBSAL), 37007 Salamanca, Spain; noemimg@usal.es (N.M.-G.); fjmoranp@usal.es (F.J.M.-P.); subadelfa@usal.es (S.B.); sheilamateos@usal.es (S.M.); carolina.caldas@usal.es (C.C.); orfao@usal.es (A.O.)

2 Biomedical Research Networking Centre Consortium of Oncology (CIBERONC), Instituto de Salud Carlos III, 28029 Madrid, Spain; villamor@clinic.cat (N.V.); abal@usal.es (A.B.);

alcocebasanchez@saludcastillayleon.es (M.A.)

3 Department of Hematology, Laboratory of Cytometry, Hospital de Santo António, Centro Hospitalar do Porto, 4099-001 Porto, Portugal; margaridalima@chporto.min-saude.pt

4 Unit for Multidisciplinary Research in Biomedicine (UMIB), Abel Salazar Institute of Biomedical Sciences (ICBAS), University of Porto, 4050-313 Porto, Portugal

5 Department of Pathology, Hematopathology Unit, Hospital Clínic, IDIBAPS, 08036 Barcelona, Spain

6 Hematology Service, University Hospital of Salamanca, Translational and Clinical Research Program, Centro de Investigación del Cáncer/IBMCC and IBSAL, 37007 Salamanca, Spain

7 Centro de Salud Miguel Armijo, Sanidad de Castilla y León (SACYL), 37007 Salamanca, Spain; aldominguezb@saludcastillayleon.es (A.D.); fgomezgar@saludcastillayleon.es (F.G.)

8 Department of Immunology, Laboratory Medical immunology, Erasmus MC, University Medical Center Rotterdam, 3015 GD Rotterdam, The Netherlands; a.langerak@erasmusmc.nl

9 Department of Immunology, Leiden University Medical Center (LUMC), 2333 ZA Leiden, The Netherlands; J.J.M.van_Dongen@lumc.nl

* Correspondence: jalmeida@usal.es

+ These authors have contributed equally to this study and should be both considered as last authors.

Simple Summary: The anti-TRBC1 antibody JOVI-1 has recently been identified as a flow cytometry marker potentially useful for assessment of T-cell clonality. The aim of this study was to optimize a flow cytometric method for routine use of anti-TRBC1 to assess T-cell clonality and validate it in a large series of normal and pathological samples. Our results showed that the best resolution to accurately identify $\mathrm{TRBC}^{+}$cells was achieved by adding the CD3 antibody either simultaneously or after TRBC1. In addition, TRBC $1^{+} / \mathrm{TRBC}^{-}$ratios within different $\mathrm{T} \alpha \beta$-cell subsets are provided as expected reference ranges for polyclonal T-cells. Based on the optimized approach here proposed, we detected monoclonal $\mathrm{T} \alpha \beta$-cell populations with high specificity (96\%) and a high analytical sensitivity/level of detection $\left(\leq 10^{-4}\right)$, when clonal T-cells exhibited immunophenotypic aberrancies. These findings further support and extend previous observations about the utility of TRBC1 for the diagnostic screening and monitoring of clonal $\mathrm{T} \alpha \beta$-cell populations.

Abstract: A single antibody (anti-TRBC1; JOVI-1 antibody clone) against one of the two mutually exclusive T-cell receptor $\beta$-chain constant domains was identified as a potentially useful flowcytometry (FCM) marker to assess T $\alpha \beta$-cell clonality. We optimized the TRBC1-FCM approach for detecting clonal $\mathrm{T} \alpha \beta$-cells and validated the method in 211 normal, reactive and pathological samples. TRBC1 labeling significantly improved in the presence of CD3. Purified TRBC1 ${ }^{+}$and TRBC1 ${ }^{-}$monoclonal and polyclonal T $\alpha \beta$-cells rearranged TRBJ1 in 44/47 (94\%) and TRBJ1+TRBJ2 in 48 of $48(100 \%)$ populations, respectively, which confirmed the high specificity of this assay. Additionally, $\mathrm{TRBC} 1^{+} / \mathrm{TRBC}^{-}$ratios within different $\mathrm{T} \alpha \beta$-cell subsets are provided as reference 
for polyclonal cells, among which a bimodal pattern of TRBC1-expression profile was found for all $\mathrm{TCRV} \beta$ families, whereas highly-variable $\mathrm{TRBC} 1^{+} / \mathrm{TRBC} 1^{-}$ratios were observed in more mature vs. naïve T $\alpha \beta$-cell subsets (vs. total T-cells). In 112/117 (96\%) samples containing clonal T $\alpha \beta$-cells in which the approach was validated, monotypic expression of TRBC1 was confirmed. Dilutional experiments showed a level of detection for detecting clonal $\mathrm{T} \alpha \beta$-cells of $\leq 10^{-4}$ in seven out of eight pathological samples. These results support implementation of the optimized TRBC1-FCM approach as a fast, specific and accurate method for assessing T-cell clonality in diagnostic-FCM panels, and for minimal (residual) disease detection in mature $\mathrm{T} \alpha \beta^{+}$leukemia/lymphoma patients.

Keywords: TRBC1; JOVI-1; T-CLPD; T $\alpha \beta$-cells; TRBJ1 and TRBJ2; TCRV $\beta$; MRD1

\section{Introduction}

T-cell chronic lymphoproliferative disorders (T-CLPD) are uncommon lymphoid malignancies (approximately 10-15\% of all peripheral/mature lymphoid neoplasms worldwide) derived from post-thymic T-cells [1,2], which comprise a heterogeneous group of entities with variable clinical behavior [1,3] and biologic features [4-8]. Diagnosis of TCLPD in cases with lymphocytosis or suspected T-cell populations is often challenging due to the lack of fast and reproducible routine diagnostic assays for T-cell clonality together with the morphologic and immunophenotypic similarities between malignant/clonal Tcells and normal (reactive) polyclonal T-cells in a significant fraction of the patients. This contrasts with assessment of B-cell clonality for which fast flow cytometry (FCM) approaches, through demonstration of (either kappa or lambda) restricted expression of light chain immunoglobulins, have been available for several decades [9]. Therefore, the availability of a similarly simple, fast, and reliable approach for assessment of T-cell clonality would be strongly welcomed.

Currently, FCM-based T-cell receptor V $\beta$ (TCRV $\beta$ ) repertoire and/or polymerase chain reaction (PCR)-based TRB and/or TRG gene rearrangement analysis assays are used to assess the clonal nature of suspicious T-cell populations in the diagnostic work-up of T-CLPD [10]. However, both approaches show limitations for routine implementation. The TCRV $\beta$-FCM assay is relatively expensive, labor-intensive, provides results which might be difficult to interpret for nonreference centers and unexperienced flow cytometrists (particularly in case of oligoclonal expansions and clones with dim TCR expression), and it has a limited sensitivity [11-13]. In turn, TR gene rearrangement analysis by PCR is relatively complex and time-consuming (requires experienced personnel and results are generally not available on the same day), does not provide accurate quantitation of the size of the T-cell clone, and/or lacks simultaneous information about the phenotypic characteristics of the expanded clone, which needs to be discriminated from the background of polyclonal T-cells $[14,15]$; sometimes it might even require prior enrichment/isolation of the suspicious clonal T-cell population to reach enough sensitivity $[14,16,17]$. Furthermore, both FCM and PCR assays are not routinely available in many diagnostic laboratories due to the low prevalence of T-CLPD.

Recently, a single antibody (TRBC1-binding monoclonal antibody, clone JOVI-1) against one of the two mutually exclusive TCR $\beta$ chain constant domains (TRBC1 and TRBC2) randomly selected during rearrangement of the TRB gene, has been proposed as a potential marker for rapid assessment of T $\alpha \beta$-cell clonality by FCM [18]. Normal, as well as virus-specific T $\alpha \beta$-cells, show an admixture of TRBC1-positive (37-51\% and $36-52 \%$ of normal CD4 ${ }^{+}$and $\mathrm{CD} 8^{+}$T-cells, respectively) [18-22] and TRBC1-negative (presumably TRBC2 positive) T-cells (polyclonal profile in GeneScan studies), whereas monoclonal $T \alpha \beta$-cells typically showed restricted (monotypic) TRBC1 expression [18-21,23-25]. Recent reports have further shown the potential utility of this antibody reagent for routine assessment of T $\alpha \beta$-cell clonality in T-CLPD vs. normal/reactive conditions [18-21,23-26]. Despite this, optimal standardization of the technique for routine use in diagnostic lab- 
oratories, and interpretation of the results based on normal reference $\mathrm{TRBC} 1^{+} / \mathrm{TRBC} 1^{-}$ ratios and ranges for both normal and reactive $T \alpha \beta$-cells (and their subsets), have not been provided. Similarly, the demonstration of both the specificity and (analytical) sensitivity of FCM assessment of the TRBC1-expression profile of T $\alpha \beta$-cells for detecting clonal T $\alpha \beta$ cells present at low numbers, including the validation of the TRBC1 assay against the gold standard (i.e., PCR) in normal/reactive vs. pathological samples, are still missing.

In this study, we optimized the TRBC1-based FCM approach for identification of clonal T $\alpha \beta$-cells by: (i) standardizing the TRBC1 staining protocol; (ii) defining the TRBC1expression profile (i.e., TRBC $1^{+} / \mathrm{TRBC}^{-}$ratios) of normal (total) T $\alpha \beta$-cells and their T $\alpha \beta$-cell subsets, defined according to CD4 and CD8 expression, TCRV $\beta$ family expression and T-cell maturation stages, and (iii) evaluating its (analytical) sensitivity and specificity for detection of clonal $\mathrm{T} \alpha \beta$-cells present at minimal disease levels. Our ultimate goal was to standardize and validate the utility of the optimized TRBC1-FCM assay for routine detection of T-cell clonality by FCM in a large cohort of normal and reactive vs. pathological samples.

\section{Materials and Methods}

\subsection{Patients, Controls and Samples}

A total of 211 EDTA-anticoagulated samples (from 211 different subjects) were collected between November 2019 and March 2021, consisting of 192 peripheral blood (PB), nine skin (SK), five bone marrow (BM), four lymph node (LN) and one abdominal mass (AM) specimens. From them, 92 PB samples were collected from adult healthy donors (HD), 10 of whom (11\%) showed a clonal T $\alpha \beta$-cell population, identified for the first time in this study by the new TRBC1 assay, and 32 from subjects with reactive expansions of $\mathrm{T}$ lymphocytes. Their mean ages $( \pm 1 S D)$ were $43 \pm 10$ years $(y), 52 \pm 13$ y and $52 \pm 21 \mathrm{y}$, for $\mathrm{HD}$, otherwise-HD with a T $\alpha \beta$-cell clone (HDc) and individuals with reactive lymphocytosis, respectively. The remaining 87 specimens were obtained from patients with different diagnostic subtypes of T-CLPD (mean age of $64 \pm 16$ y) (Table 1).

Table 1. Number of T-CLPD cases $(n=87)$, analyzed according to their WHO2017 diagnosis.

\begin{tabular}{cc}
\hline Diagnosis & n. of Cases \\
\hline T-PLL & 10 \\
PCTCL-SS & 16 \\
PCTCL-MF & 6 \\
PCTCL-NOS & 1 \\
PTCL-AITL & 2 \\
Extranodal NK/T-lymphoma, nasal type & 1 \\
PCTCLPD-small/medium CD4 & 2 \\
Hemophagocytic syndrome & 1 \\
PTCL-NOS & 2 \\
T-LGLL & 40 \\
T-CLPD not classified & 6 \\
\hline
\end{tabular}

Abbreviations (alphabetical order): AITL, angioimmunoblastic T-cell lymphoma; CLPD, chronic lymphoproliferative disorder; MF, mycosis fungoides; $n$., number; NOS, not otherwise specified; PCTCL, primary cutaneous T-cell lymphoma; PCTCLPD, primary cutaneous T chronic lymphoproliferative disorder; PTCL, peripheral T-cell lymphoma; SS, Sézary syndrome; T-LGLL, T-cell large granular lymphocyte leukemia; T-PLL, T-cell prolymphocytic leukemia; WHO, World Health Organization.

The precise distribution of samples and the study groups corresponding to the different sets of experiments performed are detailed in Supplementary Material (Supplementary Methods and Figure S1).

\subsection{General Immunophenotypic Approach}

All samples were immunophenotyped using a direct immunofluorescence stain-andthen-lyse technique, based on the EuroFlow standard operating procedures (SOP) for staining of cell surface markers only [27-29], with modifications described below for 
the different conditions tested during optimization of the TRBC1 assay. Immediately after completion of sample preparation, stained cells were measured in FACSCanto II or LSRFortessa X-20 flow cytometers (Becton/Dickinson Biosciences (BD), San Jose, CA, USA) equipped with the FACSDiva ${ }^{\mathrm{TM}}$ software (BD), or in a 5-laser Cytek ${ }^{\circledR}$ Aurora spectral flow cytometer (Cytek Biosciences, Fremont, CA, USA), using the SpectroFlo ${ }^{\circledR}$ software (Cytek Biosciences, Fremont, CA, USA). Instrument setup, calibration and daily quality control, as well as monitoring, were performed according to well-established EuroFlow protocols $[28,29]$. For data analysis, the INFINICYT ${ }^{\mathrm{TM}}$ software (Cytognos, Salamanca, Spain) was used.

\subsection{Optimization of TRBC1 Staining for Flow Cytometry}

In a first step, competition assays with distinct purified CD3 clones (SK7 or UCHT1) and fluorochrome-conjugated CD3 clones (SK7, REA613 and UCHT1) were performed in paired aliquots of six PB samples from HDs (Table S1A), as detailed in Supplementary Methods.

The potential steric hinderance between surface membrane CD3 and TRBC1 was subsequently tested in paired aliquots of 11 HD PB samples under four different staining conditions: (a) staining with TRBC1 only; and with both CD3 and anti-TRBC1 reagents where CD3 was added; (b) 10 min after the anti-TRBC1 reagent; (c) simultaneously or (d) $10 \mathrm{~min}$ before TRBC1. Different fluorochrome-conjugated anti-TRBC1 and CD3 reagents were tested. Additional conditions were evaluated to compare the number of washing steps (1 vs. 2) and the time of staining after sample collection (immediately and at $24 \mathrm{~h}, 48 \mathrm{~h}$ and $72 \mathrm{~h}$ ), as detailed in Supplementary Material (Supplementary Methods and Table S1).

The steric interaction between TCRV $\beta$ and TRBC1 was also evaluated in two PB samples from HDs for each of the 24 TCRV $\beta$ families included in the IOTest ${ }^{\circledR}$ Beta Mark TCRV $\beta$ Repertoire Kit (Beckman Coulter, Brea, CA, USA) under three different incubation conditions (Supplementary Methods and Table S1E).

The sources and specificities of all Mab reagents used for the immunophenotypic assays are detailed in Table S2. For evaluation of TRBC1 staining, both the percentage of TRBC1-positive cells from all TCR $\alpha \beta$-cells, as well as their stain index (SI), were calculated [30]. The gating strategy employed for the identification of the different TRBC1positive T-cell populations was carried out by selecting the most intense data peak in either a single TRBC1 parameter histogram or a 2 D (CD3 or CD4 or CD8 vs. TRBC1) dot-plot.

\subsection{PCR-Based Detection of TRBJ1 or TRBJ2 Gene Rearrangements in FACS-Sorted T $\alpha \beta$-Cell Populations}

Confirmation of mutually exclusive TRBC1 vs. TRBC2 gene usage in different populations of T $\alpha \beta$-cells with a TRBC1-positive vs. TRBC1-negative phenotype was assessed in genomic DNA extracted from 95 FACS-sorted (FACSAria III, BD Biosciences, San Jose, CA, USA) $\mathrm{CD}^{+} \mathrm{T} \alpha \beta C D 4^{+}$and $\mathrm{T} \alpha \beta C D 8^{+}$cell populations from 28 different individuals (purity $\geq 95 \%$ ) that showed optimal PCR amplification of the TRBJ gene product based on the presence of single TRBJ1 vs. double TRBJ1+TRBJ2 gene rearrangement patterns, respectively. For this purpose, well-established EuroClonality/BIOMED-2 primers, protocols and criteria [15] were used, based on the fact that both TRBC genes are preceded by the corresponding TRBJ genes (TRBC1 is preceded by six TRBJ1 genes while TRBC2 is preceded by seven TRBJ2 genes; Figure 1) [31,32]. For these studies, either the GenElute ${ }^{\mathrm{TM}}$ Mammalian Genomic DNA Miniprep Kit (Sigma-Aldrich, St Louis, MO, USA) or the Genomic Tissue DNA Kit (ThermoFisher Scientific, Waltham, MA, USA) were used, as per the instructions of the manufacturers. 


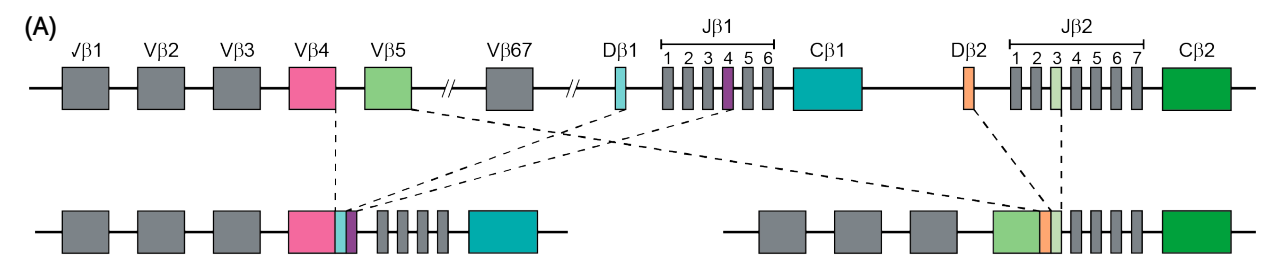

(B)

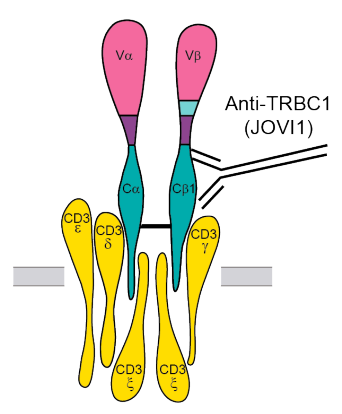

(D)

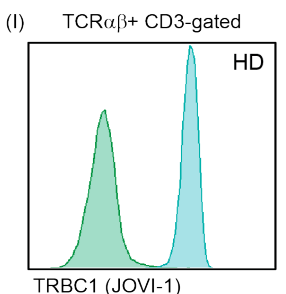

(II)

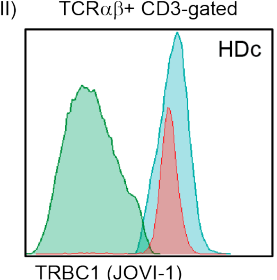

(C)

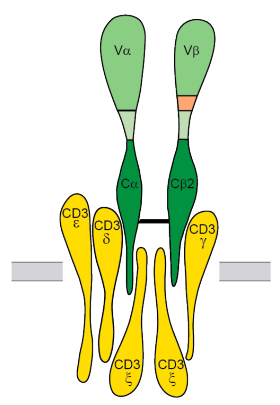

(III) TCR $\alpha \beta+C D 3$-gated

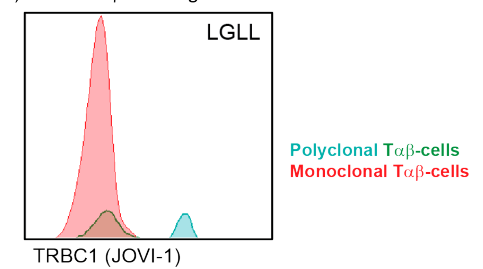

Figure 1. Schematic representation of TRB gene rearrangement and interpretation of the TRBC1 antibody (JOVI-1 clone)-based flow cytometry approach: (A) Mutually exclusive TRBC selection during TRB gene rearrangement in the thymus; $(B, C)$ Representation of the two resulting TRB complex structures, composed of either the TRBC1 (B) or the TRBC2 (C) proteins, and specific binding of the anti-TRBC1 antibody to TRBC1 but not to TRBC2; (D) Illustrative histograms of TRBC1 staining of blood T $\alpha \beta$-cells from: (I) one representative adult HD, showing the bimodal TRBC1 expression pattern, typical of polyclonal T $\alpha \beta$-cells $\left(\mathrm{TRBC}^{+}\right.$in light blue and $\mathrm{TRBC} 1^{-}$in green); (II) one HDc showing a minor $\mathrm{TRBC}^{+}$(clonal) T $\alpha \beta$-cell population (in red), among a majority of polyclonal T $\alpha \beta$-cells; and (III) one LGLL case with a major population of TRBC1 ${ }^{-}$monoclonal $\mathrm{T} \alpha \beta$-cells (in red) with a minor background of polyclonal T $\alpha \beta$-cells. Monoclonal T-cells were selected by the presence of a phenotypic aberrancy and/or expression of a single TCRV $\beta$ family, both in HDc (e.g., $\mathrm{CD} 8^{+} \mathrm{TCRV} \beta 16^{+}$) and in LGLL (e.g., $\mathrm{CD}^{+} \mathrm{CD} 279^{++}$) cases. Abbreviations (alphabetical order): $\mathrm{HD}$, healthy donor; HDc, healthy donor with a small T $\alpha \beta$-cell clone in blood; LGLL, large granular lymphocytic leukemia.

2.5. Analysis of the TRBC1 ${ }^{+} / \mathrm{TRBC1}{ }^{-}$Ratio in Distinct Subsets of Normal T $\alpha \beta$-Cells Defined by the TCRV $\beta$ Family Expressed and Their Maturation Stage

Both within total $\mathrm{T} \alpha \beta$-cells and their major $\left(\mathrm{T} \alpha \beta \mathrm{CD} 4^{+}, \mathrm{T} \alpha \beta \mathrm{CD} 8^{+}, \mathrm{T} \alpha \beta \mathrm{DP}\right.$ and $\mathrm{T} \alpha \beta \mathrm{DN}$ cells) subsets, the TRBC1 $1^{+} / \mathrm{TRBC}^{-}$ratio within each cell population defined by the expression of the different TCRV $\beta$ families was analyzed in a group of 27 PB samples (12 HD, 10 patients with reactive lymphocytosis and five HDc whose clonal T-cell populations were excluded from the analysis), stained with the IOTest ${ }^{\circledR}$ Beta Mark TCRV $\beta$ Repertoire Kit (Beckman Coulter), following the CD3-10 min-TRBC1 and the TRBC1-10 min-TCRV $\beta$ conditions described in Supplementary Material (Table S1F).

In turn, the $\mathrm{TRBC} 1^{+} / \mathrm{TRBC}^{-}$ratio for the distinct maturation-associated compartments of normal $\mathrm{T} \alpha \beta$-cells (i.e., naïve, central memory, transitional memory, effector memory, early effector and terminal effector T-cells and regulatory T-cells), identified according to the phenotypic profile shown in Table S3, was investigated in PB samples from 10 HD (Table S1G). 
2.6. Assessment of T-Cell Clonality on FACS-Sorted Cell Populations for Patients with T-CLPD vs. Reactive Lymphocytosis and Healthy Donors

The (mono)clonal vs. polyclonal nature of $\mathrm{T} \alpha \beta$-cell populations from patients with T-CLPD and reactive lymphocytosis, as well as HD (including the small T $\alpha \beta$-cells clones from HDc, and the different maturation-associated compartments of T $\alpha \beta$-cell populations from HD) was assessed in highly-purified ( $\geq 95 \%$ purity) FACS-sorted cells (purified from 3-5 mL of whole blood using a FACSAria-III cell sorter, BD Biosciences, San Jose, CA, USA), as previously described $[10,14,15]$, based on the presence (vs. absence) of single vs. a few dominant TRB and/or TRG gene rearrangements for clonal and oligoclonal/polyclonal cell subsets, respectively. In one T-cell large granular lymphocyte leukemia (T-LGLL) patient and five T-cell prolymphocytic leukemia (T-PLL) patients, T-cell clonality was further established on purified cells through confirmation of the presence of STAT3 (somatic) mutations and the demonstration of TCL1 (or MTCP1) gene translocations, respectively mboxciteB1-cancers-1320004,B33-cancers-1320004,B34-cancers-1320004.

\subsection{Validation of the TRBC1-FCM Assay against Conventional Molecular and FCM Techniques for Detection of Clonal T $\alpha \beta$-Cells}

The specificity of the TRBC1-FCM assay for identification of (true) polyclonal vs. monoclonal cell populations was validated using different fluorochrome conjugates, BV421, BV480, dyomics (Dy) 634 or FITC, of the anti-TRBC1 antibody reagent in 24 poly/oligoclonal and 93 monoclonal samples, as determined by the TCRV $\beta$ Repertoire FCM Kit, PCR [15] and/or by the presence of specific gene mutations (e.g., STAT3 mutations in T-LGLL). Of the $89 / 93$ (mono)clonal samples (96\%) a final WHO diagnosis [1] was available in 79 T-CLPD cases, while the other 10 cases concerned HDc samples.

\subsection{Serial Dilution Experiments of Pathological T $\alpha \beta$-Cells in Normal Blood Cells}

The sensitivity of the TRBC1-FCM approach for detecting clonal T $\alpha \beta$-cells was determined using both real and in silico serial dilutional experiments of PB samples (or FCM events) from T-CLPD tumor cells in normal PB. For this purpose, a total of eight experiments were performed in six patients, including parallel real and in silico dilutions in two out of six cases, and four in silico dilutions carried out in the other four cases. In all cases, dilution of the T-CLPD patient blood in PB samples from HD at 1:10, 1:100, 1:1000 and 1:10,000 tumor cells/normal cell ratios were performed. In each case, the pathological population was identified based on the presence of an aberrant phenotype (e.g., $\mathrm{CD}^{-}$) plus restricted expression of a single TCRV $\beta$ family, without using the TRBC1 staining for selection of the suspicious cell population. Per dilutional experiment $\geq 500,000$ target cells were acquired and a minimum of 50 clustered cellular events were required to consider them as a cell population.

\subsection{Statistical Methods}

The nonparametric Mann-Whitney U test and the Spearman's correlation test (for continuous variables), together with the Fisher exact test (for categorical variables), were used for group comparisons, performed with the IBM-SPSS software (v25.0; IBM, Armonk, NY, USA) and/or GraphPad Prism software (v5.01; GraphPad, San Diego, CA, USA). Prior to the comparisons, conventional normality tests (Q-Q plots, P-P plots and Kolmogorov-Smirnov test) were used to check for the normal (Gaussian) distribution of individual variables. $p$-values $\leq 0.05$ were considered to be associated with statistical significance.

\section{Results}

\subsection{Optimization of TRBC1 Staining by FCM}

A significant decline of median fluorescence intensity (MFI) values for the fluorochromeconjugated SK7, REA613 and UCHT1 CD3 clones was observed when the purified (unconjugated) SK7 and UCHT1 clones had been added prior to staining for all antibody clone combinations tested in the competition assays, compared to both simultaneous addition 
of a mixture of the purified (unconjugated) and fluorochrome-conjugated antibodies and particularly, addition of fluorochrome-conjugated CD3 reagents $10 \mathrm{~min}$ before the purified antibodies (Figure 2A,B). These results support that all clones tested recognize the same (or overlapping) CD3 epitope, as previously reported for e.g., SK7 and UCHT1 [35].
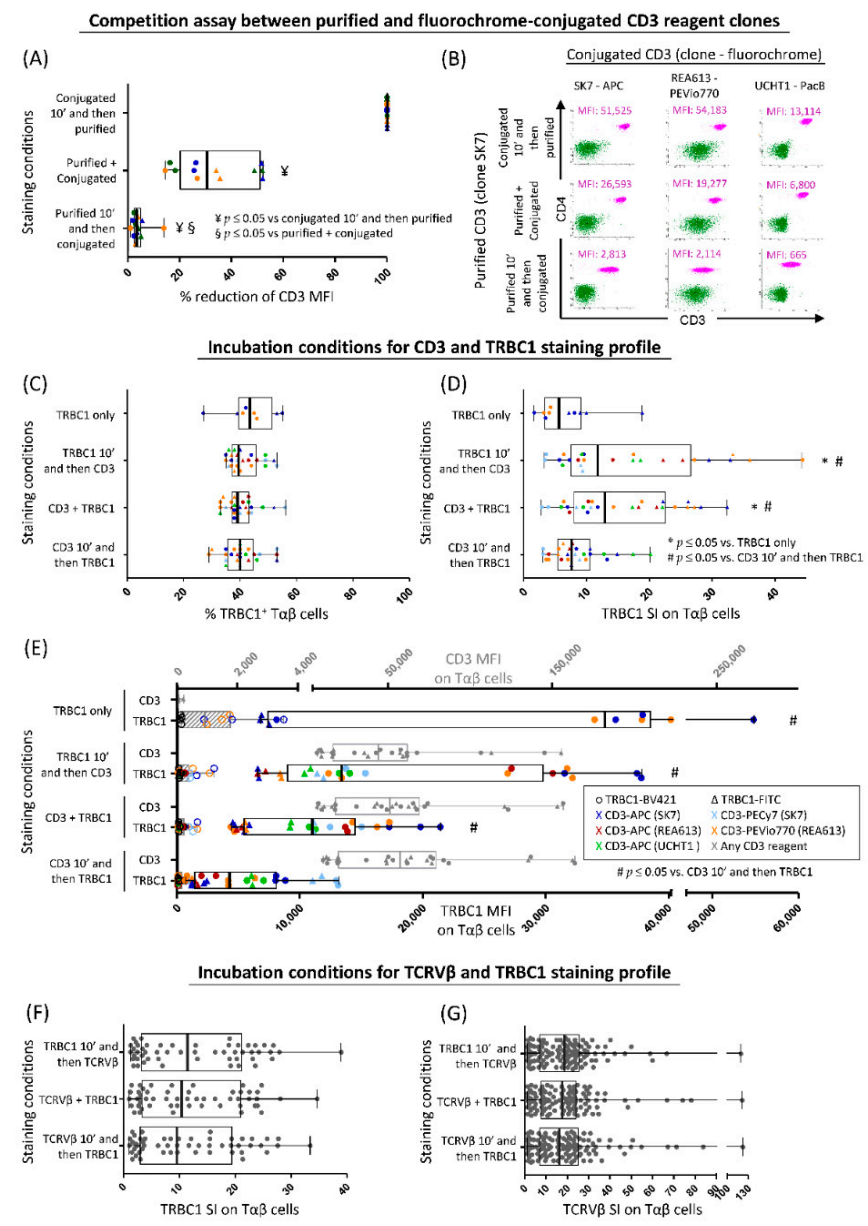

Figure 2. Impact of CD3 and TCRV $\beta$ antibody staining on the expression profile of TRBC1. (A) Competition assays performed in 6 paired PB samples stained with different fluorochrome-conjugated CD3 clones $(n=3$, SK7, REA613 and UCHT1) and unconjugated (=purified) CD3 reagents (SK7 and UCHT1) clones, tested under three different incubation conditions: (a) addition of the conjugated reagent first followed by a $10 \mathrm{~min}$ incubation before the unconjugated antibody was added; (b) simultaneous addition of the fluorochrome-conjugated and unconjugated antibody reagents; and (c) addition of the unconjugated reagent first (10 min before) followed by the fluorochrome-conjugated reagent ( $p$-value $\leq 0.05$ for $¥$ purified + conjugated vs. conjugated $10^{\prime}$ and then purified reagent, and for $\S$ purified $10^{\prime}$ and then conjugated vs. purified + conjugated reagent). (B) Illustrative graphical dot-plots of $\mathrm{T} \alpha \beta C D 4^{+}$cells (pink dots) and B cells (dark green dots) stained in competition assays described in A; (C-E) percentage of TRBC1 ${ }^{+}$T $\alpha \beta$-cells and the SI and MFI of TRBC1 ${ }^{+}$ T $\alpha \beta$-cells stained under four different conditions (staining with TRBC1 only vs. both CD3 and TRBC1 where CD3 was added $10^{\prime}$ after, simultaneously or $10^{\prime}$ before TRCB1) ( $p$-value $\leq 0.05$ for * any condition vs. TRBC1 only and for \# any condition vs. CD3 10' and then TRBC1); (F-G) Comparison of 3 different incubation conditions for the TRBC1 and TCRV $\beta$ antibody reagents are displayed as SI for TRBC1 and TCRV $\beta$ reagents as readout, respectively. Symbols and color codes in panels A-E are as follows: TRBC1-FITC, triangle; TRBC1-BV421, circle; CD3-APC-SK7, dark blue; CD3-PECy7-SK7, light blue; CD3-APC-REA613, dark red; CD3-PEVio770-REA613, orange; and CD3-APC-UCHT1, light green; gray identifies any CD3 reagent. In the box-plot graphics, dots correspond to results from individual experiments while notched boxes represent 25th and 75th percentile values, lines inside the box correspond to median values (50th percentile) and whiskers represent minimum and maximum values. Stain index (SI) was calculated as $\left(\mathrm{MFI}_{\mathrm{PP}}-\mathrm{MFI}_{\mathrm{NP}}\right) / 2 \times \mathrm{rSD}_{\mathrm{NP}}$ where MFI represents median fluorescence intensity values (arbitrary units scaled from 0 to 262,144), rSD is the robust standard deviation, and PP and NP are used as abbreviations for the TRBC1 positive and the TRBC1 negative T $\alpha \beta$-cell populations, respectively. Other abbreviations (alphabetical order): APC, allophycocyanin; BV, brilliant violet; Cy, cyanin; FITC, fluorescein-5-isothiocyanate; $\mathrm{PacB}$, pacific blue; $\mathrm{PB}$, peripheral blood; $\mathrm{PE}$, phycoerythrin. 
Staining with TRBC1 in the absence of CD3 was associated with clear staining of a fraction of the lymphocytes, but unwanted levels of background fluorescence in another subset of the lymphoid T-cells. This led to relatively low SI (Figure 2C, D). In turn, staining for TRBC1 in the presence (vs. absence) of CD3 was associated with a significantly improved discrimination between $\mathrm{TRBC}^{+}$vs. TRBC1 ${ }^{-} \mathrm{T} \alpha \beta$-cells and significantly higher SI; despite this, absence of $\mathrm{CD} 3$ did not impact the percentage of $\mathrm{TRBC} 1^{+} \mathrm{T} \alpha \beta$-cells identified (Figure 2C,D). When we compared different incubation conditions for the CD3 and TRBC1 double-staining on the TRBC1 expression profile in terms of both SI and MFI of the TRBC1 ${ }^{+}$ and TRBC1 ${ }^{-}$T $\alpha \beta$-cell populations (Figure 2D,E), we found that addition of TRBC1 either prior or simultaneously to (but not after) CD3 was associated with the highest TRBC1 SI on T $\alpha \beta$-cells and, thereby, a more clear discrimination between TRBC $1^{+}$and $\mathrm{TRBC} 1^{-}$ T $\alpha \beta$-cells (Figure 2D) was observed, with progressively decreased MFI values of TRBC1 ${ }^{+}$ at the expense of greater $(p<0.05)$ CD3 MFI values in T $\alpha \beta$-cells (Figure $2 \mathrm{E}$ ). Of note is that a similar staining profile was observed for the different CD3 clones, as well as CD3 and TRBC1 fluorochrome conjugates tested (Figures 2C-E and S2).

In contrast to the lower TRBC1 SI found when CD3 was added prior to TRBC1, no impact $(p>0.05)$ was observed on the TRBC1 SI when TCRV $\beta$ reagents were added first (prior to TRBC1), for any of the other incubation conditions tested; likewise, the TCRV $\beta$ SI was similar for all staining conditions evaluated (Figures 2F,G and S2).

Additional testing concerning the number of washing steps showed that performing 1 vs. 2 washes after adding the lysing solution did not have an impact on the TRBC1 SI (Figure S2). Similarly, TRBC1-FITC labeling did not decrease with time (vs. 0 h) even when sample staining was performed $72 \mathrm{~h}$ after blood collection, while the TRBC1-BV421 SI was significantly reduced when samples were stained $48 \mathrm{~h}$ after collection or later (Figure S2).

\subsection{TRBJ Gene Rearrangements in FACS-Sorted TRBC1 ${ }^{+}$and/or TRBC1- T $\alpha \beta^{+}$-Cell Populations}

FACS-sorted TRBC1 $1^{+}$populations of total $\mathrm{T} \alpha \beta^{+}$cells showed functionally rearranged TRBJ1 sequences in 44 of 47 cell populations (94\%) investigated, while rearrangements confirming the presence of the TRBJ1+TRBJ2 gene rearrangements were found in the remaining three of $47(6 \%)$ cell populations. In contrast, FACS-sorted TRBC1- ${ }^{-}$cell populations showed rearranged genes containing both the TRBJ1 and TRBJ2 sequences in all 48 (100\%) cell populations tested at the DNA level, regardless of their clonal status (monoclonal, oligoclonal or polyclonal populations) and, therefore, of the sample origin (HD, reactive lymphocytosis, HDc or T-CLPD) (Table 2).

Table 2. TRBJ gene rearrangements of FACS-sorted TRBC1 positive and/or TRBC1 negative T $\alpha \beta^{+}$ cell populations $(n=95)$.

\begin{tabular}{|c|c|c|c|}
\hline \multirow{2}{*}{$\begin{array}{c}\text { TRBC1 Expression } \\
\text { by FCM }\end{array}$} & \multirow{2}{*}{$\begin{array}{c}\text { Clonality Status of } \\
\text { TRBC1 Stained Cell } \\
\text { Populations }{ }^{1}\end{array}$} & \multicolumn{2}{|c|}{ TRBJ Rearrangement } \\
\hline & & JB1 & $\mathrm{JB} 1+\mathrm{JB} 2$ \\
\hline \multirow{4}{*}{$\begin{array}{l}\text { Positive } \\
(n=47)\end{array}$} & Monoclonal $(n=4)$ & 4 & 0 \\
\hline & Oligoclonal $(n=3)$ & 3 & 0 \\
\hline & Polyclonal $(n=40)$ & 37 & 3 \\
\hline & TOTAL & $44 / 47(94 \%)$ & $3 / 47(6 \%)$ \\
\hline \multirow{4}{*}{$\begin{array}{l}\text { Negative } \\
(n=48)\end{array}$} & Monoclonal $\left(n=3^{2}\right)$ & 0 & 3 \\
\hline & Oligoclonal $(n=4)$ & 0 & 4 \\
\hline & Polyclonal $(n=41)$ & 0 & 41 \\
\hline & TOTAL & 0 & $48 / 48(100 \%)$ \\
\hline
\end{tabular}

All FACS-sorted cell populations (purity $\geq 95 \%$ ) showed unequivocal expression of CD3 on the cell surface membrane by FCM with optimal PCR amplification of the TRBJ gene product. Monoclonal populations were isolated from three HDc and four T-CLPD patients; oligoclonal populations from three reactive lymphocytosis, two HDc and one T-CLPD patient; and polyclonal populations from $13 \mathrm{HD}$, seven reactive lymphocytosis, four HDc and two T-CLPD patients. ${ }^{1}$ The clonal nature (mono vs. oligo vs. polyclonal) of each purified cell population was assessed by TRB gene rearrangement analysis. ${ }^{2}$ One cell population had CD 3 high expression. Abbreviations (alphabetical order): FCM, flow cytometry; N, number; PCR, polymerase chain region; TR, T-cell receptor. 


\subsection{Ranges for Polyclonal (Normal and Reactive) T $\alpha \beta$-Cells and Major T $\alpha \beta$-Cell Populations}

Total T $\alpha \beta$-cells from normal PB $(n=65 \mathrm{HD})$ showed a mean $( \pm S D)$ percentage of $\mathrm{TRBC}^{+}$cells of $39 \pm 5.8 \%$, which translated into a $\mathrm{TRBC} 1^{+} / \mathrm{TRBC}^{-}$ratio of $0.63 \pm 0.062$. Of note is this TRBC $1^{+} / \mathrm{TRBC}^{-}$ratio varied significantly for some of the major T $\alpha \beta$ cell subsets in the same set of (normal) samples: $\mathrm{T} \alpha \beta C D 4^{+}, 0.72 \pm 0.062(p=0.003)$; $\mathrm{T} \alpha \beta C \mathrm{CD} 8^{+}, 0.50 \pm 0.081(p<0.0001) ; \mathrm{T} \alpha \beta \mathrm{DP}, 0.51 \pm 0.13(p=0.001) ;$ and $\mathrm{T} \alpha \beta \mathrm{DN}, 0.38 \pm 0.11$ $(p<0.0001)$ (Table S4). In parallel, the percentage of $\mathrm{TRBC}^{+}$cells and the corresponding $\mathrm{TRBC}^{+} / \mathrm{TRBC}^{-}$ratios were also calculated for the same major PB subsets of T $\alpha \beta$-cells from subjects with reactive lymphocytosis $(n=18)$, with a similar distribution to that observed for normal PB T $\alpha \beta$-cells (Table S4). Thereby, the percentage of $\mathrm{TRBC}^{+}$cells and the $\mathrm{TRBC} 1^{+} / \mathrm{TRBC}^{-}$ratio of HD plus reactive lymphocytosis $(n=83)$ was calculated and used to derive normal range values for polyclonal (normal and reactive) cells (Table 3). For this purpose, the mean \pm 3 standard deviations, which define intervals where $99.73 \%$ of $\mathrm{TRBC}^{+} / \mathrm{TRBC}^{-}$ratios from polyclonal cells fall, were used as cut-off values for defining monoclonal vs. polyclonal T $\alpha \beta$-cell profiles (Table 3). Based on these cut-offs, the normal range for the $\mathrm{TRBC}^{+} / \mathrm{TRBC} 1^{-}$ratio for total $\mathrm{T} \alpha \beta$-cells extended from 0.25 to 1.4 ; for $\mathrm{T} \alpha \beta C D 4^{+}$cells it ranged from 0.31 to 1.6 , and for $\mathrm{T} \alpha \beta C \mathrm{CD} 8^{+}$from 0.091 to 1.6 (Table 3 ).

Table 3. Ranges for polyclonal (normal and reactive) total T $\alpha \beta$-cells and their major T $\alpha \beta$-cell populations in PB $(n=83)$ as defined by the mean percentage of $\mathrm{TRBC}^{+}$cells and the mean $\mathrm{TRBC} 1^{+} / \mathrm{TRBC} 1^{-}$ratio \pm 3 standard deviations ( $3 \mathrm{SD}$ ).

\begin{tabular}{|c|c|c|c|c|c|}
\hline \multirow{2}{*}{$\begin{array}{c}\text { T } \alpha \beta-C e l l \\
\text { Subset }\end{array}$} & \multicolumn{2}{|c|}{$\% \mathrm{TRBC}^{+}$Cells * } & \multicolumn{2}{|c|}{ TRBC1 $^{+} / \mathrm{TRBC}^{-}{ }^{-}$Ratio } & \multirow{2}{*}{$\begin{array}{c}\text { Probability (\%) of Finding A } \\
\text { Clonal T } \alpha \beta \text { Expansion When } \\
\text { TRBC1 } 1^{+} / \mathrm{TRBC}^{-} \text {Ratio is } \\
\text { Outside the Range Mean } \pm 3 \mathrm{SD} \\
\text { ( } \rho \text {-Value) }\end{array}$} \\
\hline & Mean \pm 1 SD & $\begin{array}{c}\text { Range } \\
(\text { Mean } \pm 3 \text { SD) }\end{array}$ & Mean \pm 1 SD & $\begin{array}{c}\text { Range } \\
(\text { Mean } \pm 3 \text { SD) }\end{array}$ & \\
\hline $\mathrm{T} \alpha \beta$ cells & $40 \pm 6.7$ & $20-60$ & $0.66 \pm 0.071$ & $0.25-1.4$ & \multirow{5}{*}{$\begin{array}{l}99.73 \% \\
(<0.001)\end{array}$} \\
\hline $\mathrm{T} \alpha \beta \mathrm{CD}^{+}{ }^{+}$ & $43 \pm 6.3$ & $24-62$ & $0.75 \pm 0.067$ & $0.31-1.6$ & \\
\hline $\mathrm{T} \alpha \beta \mathrm{CD}^{+}$ & $35 \pm 8.8$ & $8.3-61$ & $0.53 \pm 0.096$ & $0.091-1.6$ & \\
\hline $\mathrm{T} \alpha \beta \mathrm{DP}$ & $36 \pm 12$ & $1.6-71$ & $0.57 \pm 0.13$ & $0.016-2.5$ & \\
\hline $\mathrm{T} \alpha \beta \mathrm{DN}$ & $29 \pm 10$ & $0-61$ & $0.41 \pm 0.12$ & $0-1.5$ & \\
\hline
\end{tabular}

* Conventional normality tests confirmed that this variable showed a Gaussian distribution. Abbreviations (alphabetical order): DN, doble negative; DP, double positive; $\mathrm{PB}$, peripheral blood; SD, standard deviation; TR, T-cell receptor.

\subsection{TRBC1 ${ }^{+} / \mathrm{TRBC1}^{-}$Ratio of Normal Polyclonal T $\alpha \beta$-Cells and Their TCRV $\beta$ and Maturation-Associated Subsets in Normal Blood}

For every TCRV $\beta$ subset of T $\alpha \beta$-cells from HD, a bimodal distribution was observed, with both $\mathrm{TRBC}^{+}$and TRBC1 ${ }^{-}$cells. However, $\mathrm{TRBC}^{+}$and $\mathrm{TRBC} 1^{-} \mathrm{T} \alpha \beta$-cells were differentially distributed according to the TCRV $\beta$ family expressed (Figure $3 \mathrm{~A}$ ). Thus, the median $\mathrm{TRBC} 1^{+} / \mathrm{TRBC}^{-}$ratio observed for $\mathrm{T} \alpha \beta$-cell subsets that expressed one of the 24 TCRV $\beta$ families ranged from 0.56 to 1.1 (Figure $3 \mathrm{~A}$ ). As expected, a bimodal TRBC1 expression profile was also observed when the analysis was restricted to the major subsets of T $\alpha \beta$-lymphocytes expressing different TCRV $\beta$ families (Figure S3). Thus, $\mathrm{TRBC}^{+} / \mathrm{TRBC}^{-}$ratios for the major $\mathrm{T} \alpha \beta$-cell subsets of $\mathrm{T} \alpha \beta \mathrm{CD} 4^{+}, \mathrm{T} \alpha \beta \mathrm{CD} 8^{+}, \mathrm{T} \alpha \beta \mathrm{DP}$ and $\mathrm{T} \alpha \beta \mathrm{DN}$ cells, expressing different TCRV $\beta$ families ranged from 0.61 to 1.2 , from 0.33 to 0.85 , from 0.25 to 1.4 and from 0.25 to 0.77 , respectively (Figure S3). 


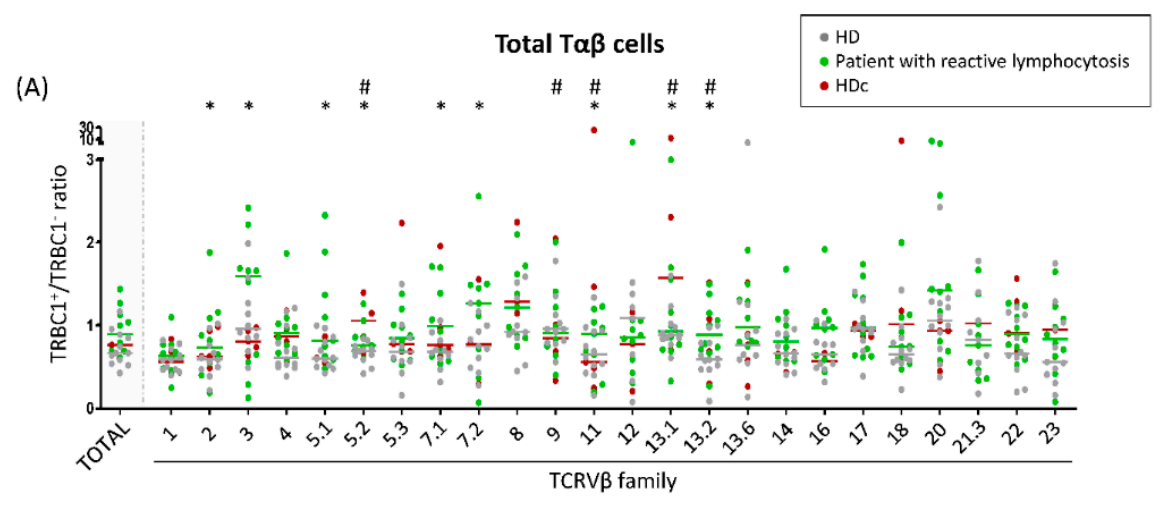

Total T $\alpha \beta$ cells

(B)

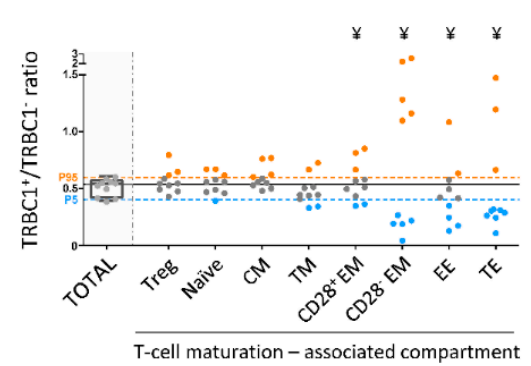

(C)

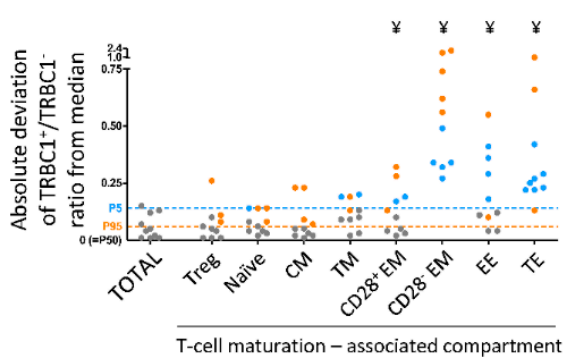

Figure 3. TRBC1 $1^{+} / \mathrm{TRBC}^{-}$ratio of normal total $\mathrm{T} \alpha \beta$-cells according to the specific TCRV $\beta$ family member expressed and their maturation stage. (A) TRBC1 $1^{+} / \mathrm{TRBC}^{-}$ratio of total T $\alpha \beta$-cells within each of the different TCRV $\beta$ families identified by immunophenotype in $12 \mathrm{HD}$ (gray dots), 10 patients with reactive lymphocytosis (green dots) and 5 otherwise healthy individuals showing a clonal expansion of Tab cells in blood (HDc, red plots). In these latter subjects, the TCRV $\beta$ clonal population was removed from analysis. Colored horizontal lines are median values of the corresponding group of subjects ( $p$-value $\leq 0.05$ for * reactive lymphocytosis vs. HD and for ${ }^{\#}$ HDc vs. HD) (B,C) $\mathrm{TRBC}^{+} / \mathrm{TRBC}^{-}$ratio observed among normal T $\alpha \beta$-cells from $10 \mathrm{HD}$, distributed into different maturation-associated compartments, represented both in individual ratio values per maturation stage (B) and their deviation from the median value (percentile $50=0 ;(\mathbf{C}))\left({ }^{¥} \rho\right.$-value $\leq 0.05$ vs. total $T \alpha \beta$-cells) In all panels, dots correspond to results from individual experiments while notched boxes represent 25 th and 75 th percentile values, lines inside the box correspond to median values (50th percentile) and whiskers represent minimum and maximum values. The continuous horizontal and dotted lines that cover the entire graph correspond to median values (percentile 50) and both the 5th and 95th percentiles (P5 and P95), respectively. Cases below P5 are depicted in blue, while cases above $\mathrm{P} 95$ are colored as orange dots. Abbreviations (alphabetical order): CM, central memory; DN, double negative (T $\left.\alpha \beta C D 4^{-}{ }^{-C D} 8^{-/ l o}\right) \mathrm{T} \alpha \beta$-cells; $\mathrm{DP}$, double positive $\left(\mathrm{T} \alpha \beta \mathrm{CD} 4^{+} \mathrm{CD} 8^{+}\right) \mathrm{T} \alpha \beta$-cells; EE, early effector; EM, effector memory; HD, healthy donor; HDc, healthy donor with a small T $\alpha \beta$-cell clone in blood; TE, terminal effector; TM, transitional memory; Treg, regulatory T-cells.

Subsequently, we investigated the $\mathrm{TRBC} 1^{+} / \mathrm{TRBC} 1^{-}$ratio distribution within different maturation-associated compartments of T $\alpha \beta$-cells from a subgroup of $10 \mathrm{HD}$ (Figure 3B). Our results showed that at earlier maturation stages (i.e., naïve, central memory and transitional memory cells as well as regulatory T $\alpha \beta$-cells) most samples were within the 5 th and 95th percentiles observed for the total population of T $\alpha \beta$-cells in normal/reactive blood. In contrast, at the more mature stages of effector memory, early effector and terminal effector $T \alpha \beta$-cells, a statistically significant number of cases were outside the normal (5th and 95th percentile) range observed for total T $\alpha \beta$-cells (i.e., more dispersed TRBC $1^{+} / \mathrm{TRBC} 1^{-}$ ratios) (Figure 3B,C). A similar profile distribution was found for $\mathrm{TRBC1}^{+} / \mathrm{TRBC}^{-}$ratios of the different $\mathrm{T} \alpha \beta$-cell subsets, meaning that in most samples earlier maturation 
stages (naïve and central/transitional memory stages) were inside the 5th and 95th percentiles observed for the total population of $\mathrm{T} \alpha \beta C D 4^{+}, \mathrm{T} \alpha \beta C D 8^{+}, \mathrm{T} \alpha \beta \mathrm{DP}$ and $\mathrm{T} \alpha \beta \mathrm{DN}$ cells (Figure S3), while more mature cell subsets mostly fell outside the 5th and 95th percentile values of total T $\alpha \beta$-cells in blood samples from HD (Figure S3).

\subsection{TRBC1 ${ }^{+} / \mathrm{TRBC1}^{-}$Ratio of Polyclonal T $\alpha \beta$-Cells Expressing Different TCRV $\beta$ Families in} Patients with Reactive Lymphocytosis and HDc Blood

A bimodal distribution of TRBC1 ${ }^{+}$and $\mathrm{TRBC}^{-}$, differentially distributed according to the specific TCRV $\beta$ family expressed, was observed among T $\alpha \beta$-cells and their major subsets in reactive lymphocytosis and HDc samples (Figure 3A and Figure S3). Thus, the median TRBC $1^{+} / \mathrm{TRBC}^{-}$ratio observed for each of the $24 \mathrm{TCRV} \beta$ families of T $\alpha \beta$ cells ranged from 0.64 to 1.6 in blood of patients with reactive lymphocytosis and from 0.54 to 1.6 in HDc (Figure 3A), with nine of 24 values (38\%) in reactive lymphocytosis cases and five of 24 values $(21 \%)$ in HDc cases samples outside the 5 th and 95th percentiles as observed in $\mathrm{HD}$ (Figure $3 \mathrm{~A}$ ). TRBC1 ${ }^{+} / \mathrm{TRBC}^{-}$ratios for the different T $\alpha \beta$-cell subsets $\left(\mathrm{T} \alpha \beta C D 4^{+}, \mathrm{T} \alpha \beta C D 8^{+}, \mathrm{T} \alpha \beta \mathrm{DP}\right.$ and $\mathrm{T} \alpha \beta \mathrm{DN}$ cells) expressing different TCRV $\beta$ families from reactive lymphocytosis and HDc are detailed in legend to Figure S3.

\subsection{Comparison between the TRBC1-FCM Assay and Conventional TCRV $\beta$-FCM and/or} Molecular Techniques for Assessment of T $\alpha \beta$-Cell Clonality

Upon comparing the TRBC1-FCM assay with the reference TCRV $\beta-F C M$ and/or molecular techniques for assessment of T $\alpha \beta$-cell clonality, concordant results were found in 112 of 117 cases $(96 \%)$ (Table 4). Concordant cases corresponded to 21 of 24 poly / oligoclonal cases $(87 \%)$ that showed a polytypic TRBC1 profile by FCM and 91 of 93 monoclonal samples $(98 \%)$ that displayed a monotypic TRBC1-FCM pattern. There were only five of 117 discrepant cases (4.3\%), either because cases that were classified as poly/oligoclonal by PCR showed a monotypic pattern of TRBC1 $(n=3)$ or because monoclonal cases by PCR showed a polytypic TRBC1 pattern $(n=2)$. Additional information on these five discrepant cases is provided in detail in Table S5 and Figure S4 and discussed below. Thus, two of three PCR polyclonal samples (cases \#1 and \#2) in whole blood, showed a monotypic TRBC1 expression with TRBC $1^{+} / \mathrm{TRBC}^{-}$ratios of $<0.01$ and $>99$ within the population(s) of phenotypically aberrant $\left(\mathrm{CD} 2{ }^{\text {lo }} \mathrm{CD} 3^{\text {lo }} \mathrm{CD} 5^{-/ \text {lo or }++}\right) \mathrm{T} \alpha \beta$-cells that represented $2.5 \%$ and $5.9 \%$ of all blood leukocytes, respectively. In the remining (discordant) sample (case \#3) classified as oligoclonal by PCR (analyzed on FACS-purified cells), a monotypic expression of TRBC1 with a TRBC1 $1^{+} / \mathrm{TRBC}^{-}$ratio of 8.0 was observed. This latter cell population phenotypically consisted of terminal-effector cytotoxic T $\alpha \beta$-cells in the absence of an immunophenotypically aberrant phenotype. Conversely, two samples (cases \#4 and \#5) analyzed in whole PB were considered monoclonal by PCR but showed a polytypic pattern of expression of TRBC1 by FCM with TRBC1 ${ }^{+} / \mathrm{TRBC}^{-}$ratios of 0.45 and 0.37 , respectively. One of these was diagnosed as reactive T-cell lymphocytosis associated with acute Epstein-Barr virus (EBV) infection (case \#4) while the second was unclassifiable (case \#5) in the absence of definitive diagnostic criteria for T-LGLL (Table S5 and Figure S4).

Table 4. Comparison between TRBC1 assay by FCM and the reference molecular and FCM techniques used to assess $\mathrm{T} \alpha \beta$-cell clonality $(n=117)$.

\begin{tabular}{cccc}
\hline Clonality Status by & \multicolumn{2}{c}{ TRBC1 Expression Pattern by FCM } & \\
\cline { 2 - 3 } Other Techniques * & $\begin{array}{c}\text { Polytypic } \\
(\boldsymbol{n}=\mathbf{2 3})\end{array}$ & $\begin{array}{c}\text { Monotypic } \\
(\boldsymbol{n}=\mathbf{9 4})\end{array}$ & $p$-Value \\
\hline Poly/oligoclonal $(n=24)$ & $\mathbf{2 1 / 2 4 ( 8 7 \% )}$ & $3 / 24(13 \%)$ & $<0.0001$ \\
Monoclonal $(n=93)$ & $2 / 93(2 \%)$ & $\mathbf{9 1 / 9 3 ( \mathbf { 9 8 } \% )}$ & \\
\hline
\end{tabular}

Concordant cases are highlighted in bold. ${ }^{*}$ Clonality assessed by PCR, TCRV $\beta$ family expression by FCM and/or gene mutation assays. Abbreviation: FCM, flow cytometry; PCR, polymerase chain region; TR, T-cell receptor. 
Patients that could be finally classified into a precise WHO diagnostic category of T-CLPD $(n=79)$, as well as HD in whom a minor population of clonal T $\alpha \beta$-cells was detected in blood in this study $(n=10)$, were divided into two groups according to their TRBC1 expression profile for the clonal T $\alpha \beta$-cells: TRBC1 ${ }^{+}$vs. TRBC1- (Table 5). Interestingly, while in T-PLL (postulated to derive from naïve/central memory cells) $\mathrm{TRBC}^{+}$only represented three of $10(30 \%)$ cases investigated, among primary cutaneous T-cell lymphoma (PCTCL)-Sézary syndrome (SS) TRBC1 ${ }^{+}$cases represented 80\% (12 of 15) of the patients, respectively (Table 5). In turn, a frequency of TRBC $1^{+}$cases of $50 \%$ and $56 \%$ was found among PCTCL-mycosis fungoides (MF) (three of six patients) and T-LGLL cases (22 of 39 patients) (Table 5). The TRBC1 expression pattern in other diagnostic categories of T-CLPD is anecdotal, due to the low number of cases investigated. Among HDc, TRBC1 was expressed in nine of $10(90 \%)$ cases identified (Table 5).

Table 5. TRBC1 expression profile in different $\mathrm{WHO}$ diagnostic categories of $\mathrm{SmCD}{ }^{+} \mathrm{T} \alpha \beta$-cell CLPD $(n=79)$ plus HDc $(n=10)$.

\begin{tabular}{ccc}
\hline WHO 2017 Diagnosis & $\begin{array}{c}\text { TRBC1 }^{+} \\
(\boldsymbol{n}=\mathbf{5 2})\end{array}$ & $\begin{array}{c}\text { TRBC1 }^{-} \\
(\boldsymbol{n}=\mathbf{3 7})\end{array}$ \\
\hline T-PLL $(n=10)$ & $3 / 10(30 \%)$ & $7 / 10(70 \%)$ \\
PCTCL-SS $(n=15)$ & $12 / 15(80 \%)$ & $3 / 15(20 \%)$ \\
PCTCL-MF $(n=6)$ & $3 / 6(50 \%)$ & $3 / 6(50 \%)$ \\
PCTCL-NOS $(n=1)$ & $0 / 1(0 \%)$ & $1 / 1(100 \%)$ \\
PTCL-AITL $(n=2)$ & $0 / 2(0 \%)$ & $2 / 2(100 \%)$ \\
Extranodal NK/T-lymphoma, nasal type $(n=1)$ & $0 / 1(0 \%)$ & $1 / 1(100 \%)$ \\
PCTCLPD-small/medium CD4 $(n=2)$ & $2 / 2(100 \%)$ & $0 / 2(0 \%)$ \\
Hemophagocytic syndrome $(n=1)$ & $0 / 1(0 \%)$ & $1 / 1(100 \%)$ \\
PTCL-NOS $(n=2)$ & $1 / 2(50 \%)$ & $1 / 2(50 \%)$ \\
T-LGLL $(n=39)$ & $22 / 39(56 \%)$ & $17 / 39(44 \%)$ \\
HDc ${ }^{*}(n=10)$ & $9 / 10(90 \%)$ & $1 / 10(10 \%)$ \\
\hline
\end{tabular}

14/52 (27\%) of TRBC1 positive cases were TRBC $1^{\text {lo }}$, and $6 / 14(43 \%)$ of TRBC $1^{\text {lo }}$ cases were CD $3{ }^{\text {lo }} .{ }^{*}$ Information about the expression profile of TRBC1 is referred to clonal cells. Abbreviations (alphabetical order): AITL, angioimmunoblastic T-cell lymphoma; CLPD, chronic lymphoproliferative disorders; HD, healthy donor; HDc, healthy donor with a small T $\alpha \beta$-cell clone in blood; MF, mycosis fungoides; NOS, not otherwise specified PCTCL, primary cutaneous T-cell lymphomas; PCTCLPD, primary cutaneous T chronic lymphoproliferative disorder; PTCL, peripheral T-cell lymphoma; Sm, surface membrane; SS, Sézary syndrome; T-LGLL, T-cell large granular lymphocyte leukemia; T-PLL, T-cell prolymphocytic leukemia; TR, T-cell receptor; WHO, World Health Organization.

\subsection{Utility of TRBC1 for Sensitive FCM Detection of Clonal T $\alpha \beta$-Cellsi in Serial Dilution Experiments of Pathological T $\alpha \beta$-Cells in Normal Blood Cells}

Serial dilution experiments $(n=8)$ of PB clonal T $\alpha \beta$-cells in normal leukocytes, performed both directly and in silico (Figure S5), showed a high degree of correlation between the percentage of clonal $\mathrm{T} \alpha \beta$-cells identified among cells that displayed an aberrant/suspicious phenotype by monotypic expression of TRBC1 vs. expression of a specific TCRV $\beta$ region $\left(R^{2}=0.966 ; p<0.001\right)$ with a sensitivity of at least $10^{-4}$ in seven of eight $(88 \%)$ dilutional experiments (Figure 4). Further identification of clonal T $\alpha \beta$-cells based on both the pattern of expression of TRBC1 and a specific TCRV $\beta$ family (vs. TRBC1 alone) showed a slightly improved correlation $\left(R^{2}=0.999 ; p<0.0001\right)$, with a sensitivity of at least $10^{-4}$ in eight of eight $(100 \%)$ experiments (Figure 4$)$. 


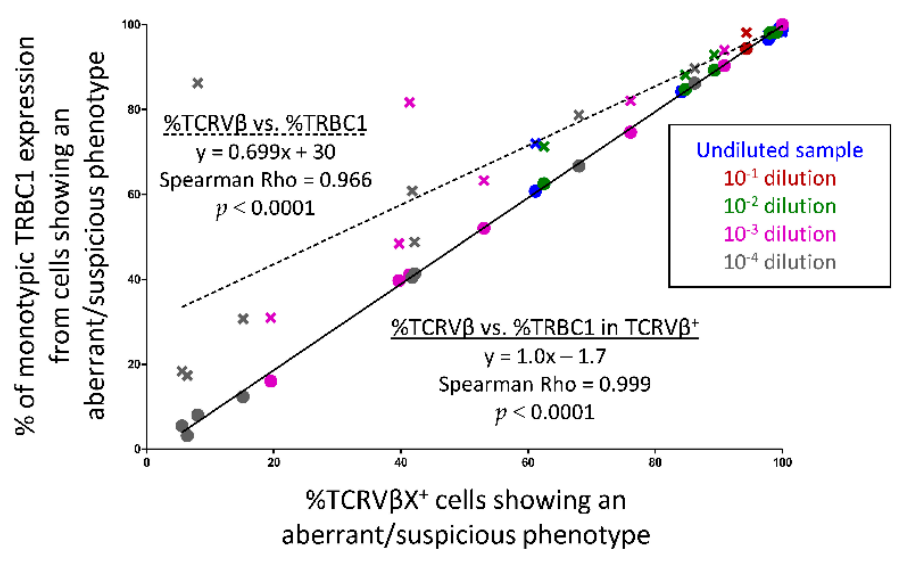

Figure 4. Sensitivity of the TRBC1 marker for detection of clonal $\mathrm{T} \alpha \beta$-cells in serial dilutional experiments of clonal tumor cells in normal blood cells. Scatter plot showing the correlation between the percentage of TCRV $\beta^{+}$vs. TRBC $1^{+}$cells (crosses and dotted line) and between the percentage of $\mathrm{TCRV} \beta^{+}$vs. (TRBC1 $1^{+}$and TCRV $\beta^{+}$) clonal cells (circles and solid line) within a specific T-cell population showing an aberrant/suspicious phenotype for both undiluted (total) samples and serially diluted (from $10^{-1}$ to $10^{-4}$ ) samples. TCRV $\beta$ X refers to any of the specific (clonal) TCRV $\beta$ family expressed by each case (e.g., TCRV $\beta 22$ ). For each correlation, the estimated linear regression equation, the Spearman's Rho correlation coefficient and the corresponding $p$-values are shown (based on 8 dilution experiments).

\section{Discussion}

Several recent reports have proposed the introduction of the TRBC1-based FCM assay as a potentially useful approach to assess $T \alpha \beta$-cell clonality in the diagnostic work-up of patients suspicious of T-CLPD [18-21,23-26]. Despite this, optimization of the antibody staining conditions, as well as reference ranges for normal and reactive polyclonal T $\alpha \beta$-cells and their major subsets, together with the sensitivity and specificity of the TRBC1 assay for detecting clonal $\mathrm{T} \alpha \beta$-cells, remain to be fully established prior to its diagnostic routine use. Here we defined the most appropriate staining conditions to obtain the best resolution between TRBC $1^{+}$and TRBC1 $1^{-}$T $\alpha \beta$-cells. In addition, we established, for the first time, reference $\mathrm{TRBC}^{+} / \mathrm{TRBC}^{-}$ranges in $\mathrm{PB}$ for normal and reactive polyclonal T $\alpha \beta$-cells and their major $\mathrm{T} \alpha \beta$-cell populations. At the same time, we provide preliminary data on the distribution of TRBC $1^{+}$and TRBC1 $1^{-}$T $\alpha \beta$-cells according to the specific TCRV $\beta$ family expressed by total $\mathrm{T} \alpha \beta$-cells (and their major subsets) and their maturation stage. Finally, we confirm and extend on previous observations $[18,21,25,26]$ about the analytical sensitivity and specificity of the assay for detecting monoclonal vs. poly/oligoclonal T $\alpha \beta$-cell populations, even when present at low frequencies in blood.

Since both CD3 and anti-TRBC1 antibodies recognize physically close epitopes of the CD3/TCR $\alpha \beta$ complex [36,37], we first tested the potential steric interaction between both groups of antibody reagents for optimization of the TRBC1 staining. Our results showed that addition of CD3 blocked the (low affinity/unspecific) binding of the antiTRBC1 reagent to $\mathrm{TRBC}^{-}$(i.e., $\mathrm{TRBC}^{+}$) T $\alpha \beta$-cells [38], while similar percentages of $\mathrm{TRBC}^{+}$cells were observed in the absence vs. presence of the CD3 Mab. This translated into an improved resolution between $\mathrm{TRBC} 1^{+}$and $\mathrm{TRBC} 1^{-}$cells when $\mathrm{CD} 3$ was added either simultaneously or after (but never before) the anti-TRBC1 antibody. These results were consistent across the different CD3 clones tested (i.e., SK7 and UCHT1) and CD3 fluorochrome-conjugated reagents. It should be noted that in some PB samples from HD, a population of T $\alpha \beta$ cells apparently showing very dim expression of TRBC1 was detected, even at different centers, (e.g., Salamanca and Porto), without paralleled low expression of CD3 (data not shown); this could be due to nonspecific labeling or any other nonidentified technical issue related to CD3/TCRV $\beta$ and TRBC1 interactions, this population being here considered as $\mathrm{TRBC}^{-}$. Further studies in FACS-sorted populations are needed to confirm 
that these cells are indeed TRBC1- (i.e., TRBC2 ${ }^{+}$). Of note is that while the TRBC1 staining profile remained stable for up to 48 hours when anti-TRBC1-FITC was used, decreased TRBC1 labelling was observed for samples aged $>48 \mathrm{~h}$ before staining with the TRBC1BV421 antibody. These results are in line with previous observations pointing out the need to stain fresh $(<48 \mathrm{~h})$ samples, also for the CD3-TRBC1 antibody pairs [27,39].

Once staining had been optimized, we subsequently validated the specificity of the TRBC1-based FCM approach based on the demonstration of TRBJ1 gene rearrangements in highly-purified TRBC1 $1^{+}$cell populations (either from monoclonal and oligo/polyclonal cases) vs. a double TRBJ1+TRBJ2 gene rearrangement pattern in purified TRBC1- ${ }^{-} \alpha \beta-$ cells, regardless of their clonal nature. Overall, our results showed a high degree of correlation between the pattern of TRBC1 protein expression and the TRBJ1 vs. TRBJ1+TRBJ2 gene rearrangement profile, except for a few discrepant samples. Of note is that such discrepant samples systematically consisted of TRBC $1^{+} \mathrm{T} \alpha \beta$-cells by FCM that displayed double TRBJ1+TRBJ2 gene rearrangements by PCR, which might be due to the presence of incomplete TRB gene rearrangements in the first allele (TRB J1-C1 and TRB J2-C2), together with a complete rearrangement of TRBJ1 on the second allele [15,40-42], as demonstrated here. In turn, all $\mathrm{TRBC1}^{-}$populations by FCM showed a first nonproductive or incomplete TRBJ1 rearrangement followed by a productive rearrangement of TRBJ2 at the DNA level of the same chromosome allele [15,40-42], which was fully consistent with the FCM assay results.

Similarly to the kappa/lambda ratio in B-CLPD $[43,44]$, the availability of reference $\mathrm{TRBC}^{+} / \mathrm{TRBC}^{-}$ratio ranges for polyclonal T $\alpha \beta$-cells, including both normal and reactive cells, is critical for routine implementation of the new TRBC1-based FCM assay in the diagnostic work-up of T-CLPD. Thus, several studies have previously reported percentage values of $\mathrm{TRBC}^{+}$cells within total T $\alpha \beta$-cells and their major TCD4 ${ }^{+}$and $\mathrm{TCD}^{+}$populations in normal blood samples $[18,20,21]$. However, different ranges are reported in these studies, due to the different nature of control samples used (HD vs. reactive blood), the limited numbers of samples investigated and/or the use of different confidence intervals (e.g., $95 \%$ CI vs. $99.7 \%$ CI) to define cut-offs for T-cell clonality. Here we defined reference TRBC1 $1^{+} / \mathrm{TRBC}^{-}$ranges for polyclonal T $\alpha \beta$-cells and all major $T \alpha \beta$-cell populations, based on the largest cohort of controls reported so far (including both HD and reactive lymphocytosis patients). In addition, more strict cut-off values with larger confidence intervals for normal cells were used for identification of clonal T $\alpha \beta$-cell expansions. Of note is that with the optimized TRBC1-FCM approach used here, small $T \alpha \beta$-cell clones were detected in a significant fraction of all HD investigated, in line with previous findings by Horna et al. [23-25]. Further molecular analysis performed here on purified suspicious $T \alpha \beta$-cells populations from these otherwise healthy individuals confirmed that they systematically corresponded to clonal cells by PCR. The significance of the presence of these T-cell clones in blood remains to be elucidated, but they could be either the result of physiologically normal immune activation of T-cells [24,26], similar to the monotypic expression of kappa or lambda in B-cells that can also be seen in skewed immune responses, without additional abnormal marker expression [44], or persistent clonal (immunosenescent) cells that does not necessarily imply malignancy, in a similar way to low-count monoclonal B lymphocytosis [45].

In order to determine whether the above reference ranges could also be applied to other major and minor $T \alpha \beta$-cell subsets, we further investigated for the first time the distribution of TRBC $1^{+}$cells within the different TCRV $\beta$ populations and maturation-associated subsets of $\mathrm{T} \alpha \beta$-cells. Although different median TRBC1 $1^{+} / \mathrm{TRBC} 1^{-}$ratios were found among cells expressing each of the TCRV $\beta$ families identified (especially in reactive cases), TRBC1 expression appeared to be independent of the specific TCRV $\beta$ family expressed among HD, as well as HDc and reactive lymphocytosis patients, i.e., a bimodal pattern was found for all families. These findings support the use of the TRBC1 expression profile as a surrogate marker of clonality in T $\alpha \beta$-cells and their major subsets, independently of the specific TCRV $\beta$ family expressed. In contrast, here we report for the first time significantly skewed 
$\mathrm{TRBC}^{+} / \mathrm{TRBC}^{-}$ratios depending on the maturation stage of $\mathrm{T} \alpha \beta$-cells. This is in contrast with previous findings by other groups who did not find differences in the percentage of $\mathrm{TRBC}^{+}$cells among distinct maturation-associated subpopulations of T $\alpha \beta$-cells, as defined by the pattern of expression of CD5, CD7 and/or CD26 [20,21,24]. Thus, the overall normal $\mathrm{TRBC}^{+} / \mathrm{TRBC}^{-}$ratio ranges of naïve, central memory, transitional memory and regulatory $\mathrm{T} \alpha \beta$-cell subsets overlapped with those of the whole $\mathrm{T} \alpha \beta$-cell populations and/or their major $\mathrm{T} \alpha \beta \mathrm{CD} 4^{+}$and $\mathrm{T} \alpha \beta \mathrm{CD} 8^{+}$subsets, whereas more mature populations of $\mathrm{CD}_{2} 8^{+}$and particularly CD28- effector memory, early effector, and terminal effector cells of $\mathrm{HD}$ displayed more heterogeneous and clear skewed $\mathrm{TRBC} 1^{+} / \mathrm{TRBC}^{-}$ratios compared with those of total T $\alpha \beta$-cells, regardless of the specific subset of, for example, $\mathrm{T} \alpha \beta C D 4^{+}$ or $\mathrm{T} \alpha \beta C D 8^{+}$cells. These findings support an increasingly higher degree of oligoclonality associated with a progressively narrower TR repertoire, along the maturation of blood $T \alpha \beta$-cells, due to the accumulation of effector T-cells specific for a relatively more limited number of antigens, including antigens from viruses that persist in the organism, such as EBV and cytomegalovirus [46]. The fact that the $\mathrm{TRBC} 1^{+} / \mathrm{TRBC}^{-}$ratio of more mature $\mathrm{T} \alpha \beta$-cell populations usually deviates from those of total $\mathrm{T} \alpha \beta$-cells from the same subject should be considered in the diagnostic work-up of T-cell clonality by FCM, particularly in the absence of phenotypic aberrations and when suspicious effector (e.g., LGL) T $\alpha \beta$ cell populations are investigated. Further analysis including larger series of samples are required to establish the precise $\mathrm{TRBC} 1^{+} / \mathrm{TRBC}^{-}$ratios within the different maturation compartments of $\mathrm{T} \alpha \beta$-cells, both in blood and in other tissues.

Validation of the pre-established normal cut-offs in a large cohort of samples, including HD, reactive lymphocytosis and T-CLPD patients, showed a high degree of correlation between the TRBC1-FCM approach and T-cell clonality results assessed by molecular and TCRV $\beta$-FCM assays, except for a few discrepant cases, in line with previous observations $[18,21,25]$. More detailed investigation of such discrepant cases showed that in three of five patients (cases \#1, \#2 and \#4), final diagnosis was concordant with the TRBC1-based FCM assay results, with failure of PCR in two of three cases (cases \#1 and \#2) to detect T-cell clonality being due to the analysis of whole blood DNA instead of the FACS-sorted (suspicious) cell population DNA, in samples where the percentage of clonal cells in PB was below the sensitivity limit of the molecular technique [15-17]. Although final diagnosis at the referring center was inconclusive in the first case (case \#1), the presence of a clearly aberrant $\left(\mathrm{CD}^{\mathrm{lo}}{ }^{\mathrm{l}}\right) \mathrm{T} \alpha \beta$ effector cell population associated with chronic neutropenia would strongly support the diagnosis of T-LGLL [33], in line with monotypic expression of TRBC1. In one of the remaining two discrepant cases (case \#3), an expansion of LGL with a normal T $\alpha \beta$-effector cell phenotype (CD2 ${ }^{+} \mathrm{CD}^{\text {lo }} \mathrm{CD} 27^{-} \mathrm{CD}^{-} 8^{-} \mathrm{CD} 4 \mathrm{RA}^{-/+}$ cytoplasmic granzyme ${ }^{+}$) [33], but an elevated $\mathrm{TRBC}^{+} / \mathrm{TRBC}^{-}$ratio compared to nor$\mathrm{mal} /$ reactive polyclonal $\mathrm{T} \alpha \beta \mathrm{CD} 8^{+}$cells was observed in the absence of clonality by PCR. In this case, the possibility that the altered $\mathrm{TRBC} 1^{+} / \mathrm{TRBC} 1^{-}$ratio might be due to an increased number of (activated-oligoclonal) senescent effector memory/terminal effector $\mathrm{T} \alpha \beta C D 8^{+}$cells $[14,15]$ could not be ruled out, since similarly increased TRBC $1^{+} / \mathrm{TRBC} 1^{-}$ ratios were observed in normal and reactive blood when analysis was restricted to normal effector memory/terminal effector T $\alpha \beta C D 8^{+}$cells. Finally, in the last discrepant case (case \#5), an aberrant $\left(\mathrm{CD}^{\text {lo }} \mathrm{CD}^{-/ 10}\right)$ terminal-effector $\left(\mathrm{CD} 28^{-} \mathrm{CD}^{-} 4 \mathrm{RA}^{+} \mathrm{CD}^{-} \mathrm{RO}^{-}\right)$phenotype suggestive of a monoclonal expansion, confirmed by PCR (but not by TCRV $\beta$-FCM analysis and the new TRBC1-FCM assay) was observed in the absence of a definitive explanation for the discordant results.

Despite the low number of T-CLPD cases analyzed within each WHO2017 diagnostic category, our results showed a potentially skewed usage of TRBC2 vs. TRBC1 in T-PLL (derived from a naïve/central memory cell [1]), that contrast with PCTCL-SS (derived from a central memory/transitional memory cell [1]) and HDc (in whom most clones corresponded to effector memory/terminal effector), which more frequently involved the TRBC1 region. Our results support previous studies in which only one out of three T-PLL cases studied were TRBC $1^{+}$[21], while differing from others, in which only $22 \%$ of 
HDc (14/63, named as T-cell clones of uncertain significance) were TRBC1 ${ }^{+}$[23] or less than $50 \%$ of SS plus MF cases (30 of 63) showed TRBC1 ${ }^{+}$[21,24]. More extensive studies including larger series of a broader number of T-CLPD diagnostic categories are required to elucidate the potentially skewed usage of TRBC1 vs. TRBC2 in different diagnostic subtypes of T-CLPD, and the precise biological significance of these findings.

Despite the diagnostic value of the new TRBC1 assay here optimized and validated, it should be noted that occasionally clonal T-cell populations show dim or negative surface CD3/TCRV $\beta$ expression levels [26]. Among those T-CLPD patients with productive gene rearrangements upstream of TRBC1, expression of TRBC1 at the protein level would be also low or negative. Thus, absence of TRBC1 expression in these patients would be due to lack of surface $\mathrm{CD} 3 / \mathrm{TRBC} 1$ expression rather than a gene rearrangement upstream of TRBC2. In this regard, it should be noted that in nearly half of our TRBC1 ${ }^{+} \mathrm{T}-\mathrm{CLPD}$ patients concordantly low expression of SmCD3 and TRBC1 was observed. In contrast, in the other half of our T-CLPD cases, clonal T $\alpha \beta$-cells showed normal expression levels of SmCD3/TCRV $\beta$ with abnormally low amounts of TRBC1 on the cell surface membrane, in the absence of an apparent cause that could explain such differences, as previously reported by other research groups $[23,25,26]$.

As described above, assessment of the TRBC1 expression profile among phenotypically aberrant populations of T $\alpha \beta$-cells allowed sensitive identification of small $T \alpha \beta$-cell clones, even among otherwise healthy donors, in line with previous findings [20,23-25]. However, the precise analytical sensitivity of the new TRBC1 FMC assay remained to be established. Thus, an additional objective of our study was to determine the level of detection of the TRBC1-based FCM approach for detecting clonal populations of T $\alpha \beta$-cells showing an aberrant phenotype, whenever present at low frequencies in blood. From a clinical point of view, a level of detection of $10^{-4}$ is currently considered sufficient for minimal/measurable (residual) disease (MRD) detection and monitoring in T-CLPD [27,47]. In this regard, here we show that assessment of the pattern of expression of TRBC1 in small populations of phenotypically aberrant $\mathrm{T} \alpha \beta$-cells from patients with distinct subtypes of T-CLPD provides a level of detection of $\leq 10^{-4}$, similar to that obtained once tumorassociated TCRV $\beta$ family-specific antibodies are used, as demonstrated by real and virtual dilutional experiments. However, combined assessment of both TRBC1 and TCRV $\beta$ family expression profiles slightly improved the sensitivity of detection of small T $\alpha \beta$-cell clones in one of our cases, and at the same time it provided more accurate MRD counts.

\section{Conclusions}

In summary, the here optimized TRBC1 approach is a useful, simple and fast FCM assay for assessment of T $\alpha \beta$-cell clonality in blood of patients suspicious of T-CLPD. At the same time, the assay is cost-effective, since we have estimated an overall cost-saving of around $80-90 \%$ per sample compared to using either the whole TCRV $\beta$ Repertoire FCM Kit or PCR-based techniques. In addition, once used in combination with tumor-associated aberrant immunophenotypes, the TRBC1 expression profile (negative vs. positive) of $\mathrm{SmCD}^{+}$cells shows a high sensitivity and specificity for detection of monoclonal $\mathrm{T} \alpha \beta$-cells in patients suspicious of T-CLPD, at similar levels to those reached with the kappa/lambda ratio in the diagnostic work-up of B-CLPD $[43,44,48]$. Optimal assessment of clonality by TRBC1 expression would require appropriate integration of the TRBC1/CD3 reagents into comprehensive lymphocyte screening panels for the diagnostic work-up of patients presenting with lymphocytosis, as well as into the current T-CLPD classification and MRD monitoring antibody panels.

Supplementary Materials: The following are available online at https:/ / www.mdpi.com/article/10 .3390 / cancers13174379/s1. Supplementary Methods. Table S1: Fluorochrome-conjugated antibody panels used in this study. Table S2: Sources and specificities of the monoclonal antibody reagents used. Table S3: Phenotypic markers associated with different maturation subsets of T-cells and the corresponding immunophenotypic profiles used for the identification of T-cell maturation stages in adult healthy donor blood. Table S4: Distribution of $\mathrm{TRBC}^{+}$cells and the TRBC1 ${ }^{+} / \mathrm{TRBC} 1^{-} \mathrm{T}-\mathrm{cell}$ 
ratio among normal and reactive $\mathrm{T} \alpha \beta$-cells and the major $\mathrm{T} \alpha \beta$-cell populations present in normal and reactive PB. Table S5: Detailed features of samples showing discrepant results between the pattern of expression of TRBC1 by FCM and the T-cell clonality status as assessed by the reference molecular and TCRV $\beta$-FCM assays ( $n=5 / 117 ; 4.3 \%$ ). Figure S1: Flowchart illustrating the distribution of samples ( $n=211$, including $192 \mathrm{~PB}, 9 \mathrm{SK}, 5 \mathrm{BM}, 4 \mathrm{LN}$ and $1 \mathrm{AM})$ and the study groups corresponding to the different sets of experiments performed. Figure S2: Pattern of expression of TRBC1 on blood T-cells using different staining conditions. Figure S3: TRBC $1^{+} / \mathrm{TRBC} 1^{-}$ratio of normal T $\alpha \beta$-cell subsets defined within the major TCD4, TCD8, TDP and TDN cell populations based on the pattern of expression of specific TCRV $\beta$ family members and their maturation stage. Figure S4: Illustrative dot-plot diagrams, clonality data and final diagnosis of cases showing discrepant results between the pattern of expression of TRBC1 by FCM and the T-cell clonality status by conventional TCRV $\beta$ FCM and/or molecular reference techniques $(n=5 / 117 ; 4.3 \%)$. Figure S5: Illustrative dot-plot diagrams of a representative dilutional experiment of clonal T $\alpha \beta$-cells from a T-LGLL patient in normal blood.

Author Contributions: Conceptualization, J.A.; A.O. and J.J.M.v.D. contributed to the conceptualization, designs, and supervision of the study, as well as to the recruitment of funding. N.M.-G., F.J.M.-P., S.B., S.M., C.C., A.B., M.A., M.L. and N.V. performed the experiments (FCM, FACS-sorting, molecular biology assays), their validations and/or the analysis and the interpretations of the results. N.M.-G. coordinated the planning and execution of the experiments. N.M.-G., M.L., N.V., S.B., A.D. and F.J.M.-P. selected cases for the study and collected their relevant clinical information; A.W.L. contributed to the design of appropriate molecular assays; M.L. and A.W.L. also provided critical input on data interpretation; N.M.-G., A.O., F.G. and J.A. wrote the manuscript. All authors have read and agreed to the published version of the manuscript.

Funding: This work was supported by the CB16/12/00400 (CIBERONC) and PI20-01346 grants, from the Instituto de Salud Carlos III, Ministerio de Ciencia e Innovación (Madrid, Spain) and FONDOS FEDER, and by the EuroFlow Foundation (Leiden, The Netherlands). N. Muñoz-García is supported by a pre-doctoral grant (Ref. IBPredoc17/00012) from IBSAL (Salamanca, Spain). M. Lima, N. Villamor, A.W. Langerak, J.J.M. van Dongen, A. Orfao, and J. Almeida are members of the EuroFlow Consortium [29].

Institutional Review Board Statement: All patients and controls gave their written informed consent to participate in the study. The project was conducted according to the guidelines of the Declaration of Helsinki and approved by the Ethics Committees of the corresponding participating hospitals (University Hospital of Salamanca/IBSAL, Salamanca, Spain; Hospital de Santo António, Centro Hospitalar do Porto, Porto, Portugal; and Hospital Clínic, Barcelona, Spain).

Informed Consent Statement: Informed consent was obtained from all subjects involved in the study.

Data Availability Statement: Exclude this statement as the study did not report any data.

Acknowledgments: The authors thank the following researchers for their assistance in collecting samples and/or for technical guidance and support at different stages of the study: Alfonso Romero, Ana Helena Santos, Guillermo Oliva, João Rodrigues, María del Carmen García-Macias, María Jara-Acevedo, Maria Eugenia Sarasquete.

Conflicts of Interest: The authors declare no competing financial interests or any other conflict of interest.

\section{References}

1. Campo, E.; Harris, N.L.; Jaffe, E.S.; Pileri, S.A.; Stein, H.; Thiele, J.; Vardiman, J.M. WHO Classification of Tumours of Haematopoietic and Lymphoid Tissues; Swerdlow, S.H., Ed.; Revised 4 t.; WHO Press: Lyon, France, 2017.

2. Armitage, J.O. A clinical evaluation of the International Lymphoma Study Group classification of non-Hodgkin's lymphoma. Blood 1997, 89, 3909-3918.

3. Vose, J.M.; Neumann, M.; Harris, M.E. International peripheral T-cell and natural killer/T-cell lymphoma study: Pathology findings and clinical outcomes international T-cell lymphoma project. J. Clin. Oncol. 2008, 26, 4124-4130. [CrossRef]

4. Jamal, S.; Picker, L.J.; Aquino, D.B.; McKenna, R.W.; Dawson, D.B.; Kroft, S.H. Immunophenotypic analysis of peripheral T-cell neoplasms: A multiparameter flow cytometric approach. Am. J. Clin. Pathol. 2001, 116, 512-526. [CrossRef]

5. Gorczyca, W.; Weisberger, J.; Liu, Z.; Tsang, P.; Hossein, M.; Wu, C.D.; Dong, H.; Wong, J.Y.L.; Tugulea, S.; Dee, S.; et al. An Approach to Diagnosis of T-cell Lymphoproliferative Disorders by Flow Cytometry. Clin. Cytom. 2002, 50, 177-190. [CrossRef] 
6. Jevremovic, D.; Olteanu, H. Flow Cytometry Applications in the Diagnosis of T/NK-Cell Lymphoproliferative Disorders. Cytom. Part B - Clin. Cytom. 2019, 96, 99-115. [CrossRef]

7. Went, P.; Agostinelli, C.; Gallamini, A.; Piccaluga, P.P.; Ascani, S.; Sabattini, E.; Bacci, F.; Falini, B.; Motta, T.; Paulli, M.; et al. Marker expression in peripheral T-cell lymphoma: A proposed clinical-pathologic prognostic score. J. Clin. Oncol. 2006, 24, 2472-2479. [CrossRef]

8. Iqbal, J.; Amador, C.; McKeithan, T.W.; Chan, W.C. T-Cell and NK-Cell Lymphomas. From Biology to Novel Therapies - Chapter: Molecular and Genomic Landscape of Peripheral T-cell Lymphoma; Querfeld, C., Zain, J., Rosen, S.T., Eds.; Springer: Cham, Switzerland, 2019; ISBN 9783319997155.

9. Flores-Montero, J.; Grigore, G.; Fluxá, R.; Hernández, J.; Fernandez, P.; Almeida, J.; Muñoz, N.; Böttcher, S.; Sedek, L.; van der Velden, V.; et al. EuroFlow Lymphoid Screening Tube (LST) data base for automated identification of blood lymphocyte subsets. J. Immunol. Methods 2019, 475, 112662. [CrossRef]

10. Langerak, A.W.; van den Beemd, R.; Wolvers-Tettero, I.L.M.; Boor, P.P.C.; van Lochem, E.G.; Hooijkaas, H.; van Dongen, J.J.M. Molecular and flow cytometric analysis of the VB repertoire for clonality assessment in mature TCRab T-cell proliferations. Blood 2001, 98, 165-174. [CrossRef] [PubMed]

11. Morice, W.G.; Kimlinger, T.; Katzmann, J.A.; Lust, J.A.; Heimgartner, P.J.; Halling, K.C.; Hanson, C.A. Flow Cytometric Assessment of TCR-V $\beta$ Expression in the Evaluation of Peripheral Blood Involvement by T-Cell Lymphoproliferative Disorders: A Comparison with Conventional T-Cell Immunophenotyping and Molecular Genetic Techniques. Am. J. Clin. Pathol. 2004, 121, 373-383. [CrossRef] [PubMed]

12. Beck, R.C.; Stahl, S.; O'Keefe, C.L.; Maciejewski, J.P.; Theil, K.S.; Hsi, E.D. Detection of Mature T-Cell Leukemias by Flow Cytometry Using Anti-T-Cell Receptor V $\beta$ Antibodies. Am. J. Clin. Pathol. 2003, 120, 785-794. [CrossRef] [PubMed]

13. Tembhare, P.; Yuan, C.M.; Xi, L.; Morris, J.C.; Liewehr, D.; Venzon, D.; Janik, J.E.; Raffeld, M.; Stetler-Stevenson, M. Flow cytometric immunophenotypic assessment of T-cell clonality by V $\beta$ repertoire analysis: Detection of T-cell clonality at diagnosis and monitoring of minimal residual disease following therapy. Am. J. Clin. Pathol. 2011, 135, 890-900. [CrossRef]

14. Langerak, A.W.; Groenen, P.J.T.A.; Brüggemann, M.; Beldjord, K.; Bellan, C.; Bonello, L.; Boone, E.; Carter, G.I.; Catherwood, M.; Davi, F.; et al. EuroClonality/BIOMED-2 guidelines for interpretation and reporting of Ig/TCR clonality testing in suspected lymphoproliferations. Leukemia 2012, 26, 2159-2171. [CrossRef] [PubMed]

15. van Dongen, J.J.M.; Langerak, A.W.; Brüggemann, M.; Evans, P.A.S.; Hummel, M.; Lavender, F.L.; Delabesse, E.; Davi, F.; Schuuring, E.; García-Sanz, R.; et al. Design and standardization of PCR primers and protocols for detection of clonal immunoglobulin and T-cell receptor gene recombinations in suspect lymphoproliferations: Report of the BIOMED-2 concerted action BMH4-CT98-3936. Leukemia 2003, 17, 2257-2317. [CrossRef]

16. Wang, H.W.; Raffeld, M. Molecular assessment of clonality in lymphoid neoplasms. Semin. Hematol. 2019, 56, 37-45. [CrossRef]

17. Schumacher, J.A.; Duncavage, E.J.; Mosbruger, T.L.; Szankasi, P.M.; Kelley, T.W. A comparison of deep sequencing of TCRG rearrangements vs. traditional capillary electrophoresis for assessment of clonality in t-cell lymphoproliferative disorders. Am. $J$. Clin. Pathol. 2014, 141, 348-359. [CrossRef]

18. Novikov, N.D.; Griffin, G.K.; Dudley, G.; Drew, M.; Rojas-Rudilla, V.; Lindeman, N.I.; Dorfman, D.M. Utility of a simple and robust flow cytometry assay for rapid clonality testing in mature peripheral T-Cell lymphomas. Am. J. Clin. Pathol. 2019, 151, 494-503. [CrossRef]

19. Maciocia, P.M.; Wawrzyniecka, P.A.; Philip, B.; Ricciardelli, I.; Akarca, A.U.; Onuoha, S.C.; Leguț, M.; Cole, D.K.; Sewell, A.K.; Gritti, G.; et al. Targeting the T cell receptor $\beta$-chain constant region for immunotherapy of T cell malignancies. Nat. Med. 2017, 23, 1416-1423. [CrossRef]

20. Shi, M.; Jevremovic, D.; Otteson, G.E.; Timm, M.M.; Olteanu, H.; Horna, P. Single Antibody Detection of T-Cell Receptor $\alpha \beta$ Clonality by Flow Cytometry Rapidly Identifies Mature T-Cell Neoplasms and Monotypic Small CD8-Positive Subsets of Uncertain Significance. Cytom. Part B - Clin. Cytom. 2020, 98, 99-107. [CrossRef] [PubMed]

21. Berg, H.; Otteson, G.E.; Corley, H.; Shi, M.; Horna, P.; Jevremovic, D.; Olteanu, H. Flow cytometric evaluation of TRBC1 expression in tissue specimens and body fluids is a novel and specific method for assessment of T-cell clonality and diagnosis of T-cell neoplasms. Cytom. Part B - Clin. Cytom. 2020, 1-9. [CrossRef]

22. Kaewpreedee, P.; Boonrat, P.; Tansiri, Y.; Rowland-Jones, S.L.; Hansasuta, P. Dimorphism in the T-cell receptor constant region affects T-cell function, phenotype and HIV outcome. Aids 2019, 33, 1421-1429. [CrossRef] [PubMed]

23. Shi, M.; Olteanu, H.; Jevremovic, D.; He, R.; Viswanatha, D.; Corley, H.; Horna, P. T-cell clones of uncertain significance are highly prevalent and show close resemblance to T-cell large granular lymphocytic leukemia. Implications for laboratory diagnostics. Mod. Pathol. 2020. [CrossRef] [PubMed]

24. Horna, P.; Shi, M.; Jevremovic, D.; Craig, F.E.; Comfere, N.I.; Olteanu, H. Utility of TRBC1 Expression in the Diagnosis of Peripheral Blood Involvement by Cutaneous T-Cell Lymphoma. J. Invest. Dermatol. 2021, 141, 821-829.e2. [CrossRef] [PubMed]

25. Horna, P.; Olteanu, H.; Jevremovic, D.; Otteson, G.E.; Corley, H.; Ding, W.; Parikh, S.A.; Shah, M.V.; Morice, W.G.; Shi, M. Single-Antibody Evaluation of T-Cell Receptor $\beta$ Constant Chain Monotypia by Flow Cytometry Facilitates the Diagnosis of T-Cell Large Granular Lymphocytic Leukemia. Am. J. Clin. Pathol. 2021, 156, 139-148. [CrossRef] [PubMed]

26. Horna, P.; Shi, M.; Olteanu, H.; Johansson, U. Emerging role of $t$-cell receptor constant $\beta$ chain- 1 (TRBC1) expression in the flow cytometric diagnosis of t-cell malignancies. Int. J. Mol. Sci. 2021, 22, 1817. [CrossRef] [PubMed] 
27. van Dongen, J.J.; Lhermitte, L.; Böttcher, S.; Almeida, J.; van der Velden, V.H.; Flores-Montero, J.; Rawstron, A.; Asnafi, V.; Lécrevisse, Q.; Lucio, P.; et al. EuroFlow antibody panels for standardized n-dimensional flow cytometric immunophenotyping of normal, reactive and malignant leukocytes. Leukemia 2012, 26, 1908-1975. [CrossRef]

28. Kalina, T.; Flores-Montero, J.; van der Velden, V.H.J.; Martin-Ayuso, M.; Böttcher, S.; Ritgen, M.; Almeida, J.; Lhermitte, L.; Asnafi, V.; Mendonça, A.; et al. EuroFlow standardization of flow cytometer instrument settings and immunophenotyping protocols. Leukemia 2012, 26, 1986-2010. [CrossRef]

29. EuroFlow. Available online: https:/ / www.euroflow.org/ (accessed on 17 June 2021).

30. Maecker, H.T.; Frey, T.; Nomura, L.E.; Trotter, J. Selecting fluorochrome conjugates for maximum sensitivity. Cytom. Part A 2004, 62, 169-173. [CrossRef]

31. Langerak, A.; Wolvers-Tettero, I.; van Dongen, J. Detection of T cell receptor beta (TCRB) gene rearrangement patterns in T cell malignancies by Southern blot analysis. Leukemia 1999, 13, 965-974. [CrossRef]

32. Droese, J.; Langerak, A.W.; Groenen, P.J.T.A.; Brüggemman, M.; Neumann, P.; Wolvers-Tettero, I.L.M.; van Altena, M.C.; Kneba, M.; van Dongen, J.J.M. Validation of BIOMED-2 multiplex PCR tubes for detection of TCRB gene rearrangements in T-cell malignancies. Leukemia 2004, 18, 1531-1538. [CrossRef]

33. Muñoz-García, N.; Jara-Acevedo, M.; Caldas, C.; Bárcena, P.; López, A.; Puig, N.; Alcoceba, M.; Fernández, P.; Villamor, N.; Flores-Montero, J.A.; et al. STAT3 and STAT5B mutations in T/NK-cell chronic lymphoproliferative disorders of large granular lymphocytes (LGL): Association with disease features. Cancers 2020, 12, 3508. [CrossRef]

34. Laribi, K.; Lemaire, P.; Sandrini, J.; de Materre, A.B. Advances in the understanding and management of T-cell prolymphocytic leukemia. Oncotarget 2017, 8, 104664-104686. [CrossRef]

35. Kastrup, J.; Pedersen, L.; Dietrich, J.; Lauritsen, J.P.H.; Menné, C.; Geisler, C. In vitro production and characterization of partly assembled human CD3 complexes. Scand. J. Immunol. 2002, 56, 436-442. [CrossRef] [PubMed]

36. Morath, A.; Schamel, W.W. $\alpha \beta$ and $\gamma \delta$ T cell receptors: Similar but different. J. Leukoc. Biol. 2020, 107, 1045-1055. [CrossRef] [PubMed]

37. Natarajan, K.; Jiang, J.; May, N.A.; Mage, M.G.; Boyd, L.F.; McShan, A.C.; Sgourakis, N.G.; Bax, A.; Margulies, D.H. The role of molecular flexibility in antigen presentation and T cell receptor-mediated signaling. Front. Immunol. 2018, 9, 1657. [CrossRef] [PubMed]

38. Tunnacliffe, A.; Kefford, R.; Milstein, C.; Forster, A.; Rabbitts, T.H. Sequence and evolution of the human T-cell antigen receptor $\beta$-chain genes. Proc. Natl. Acad. Sci. USA 1985, 82, 5068-5072. [CrossRef] [PubMed]

39. Diks, A.M.; Bonroy, C.; Teodosio, C.; Groenland, R.J.; de Mooij, B.; de Maertelaere, E.; Neirynck, J.; Philippé, J.; Orfao, A.; van Dongen, J.J.M.; et al. Impact of blood storage and sample handling on quality of high dimensional flow cytometric data in multicenter clinical research. J. Immunol. Methods 2019, 475, 112616. [CrossRef]

40. Duby, A.D.; Seidman, J.G. Abnormal recombination products result from aberrant DNA rearrangement of the human T-cell antigen receptor B-chain gene. Immunology 1986, 83, 4890-4894. [CrossRef]

41. TRBC2 Sequence. Available online: http://www.ensembl.org/Homo_sapiens/Gene/Summary?db=core;g=ENSG00000211772 ;r=7:142801041-142802748;t=ENST00000466254 (accessed on 28 June 2021).

42. TRBC1 Sequence. Available online: http://www.ensembl.org/Homo_sapiens/Gene/Summary?db=core;g=ENSG00000211751 ;r=7:142791694-142793368;t=ENST00000633705 (accessed on 17 June 2021).

43. Katzmann, J.A.; Clark, R.J.; Abraham, R.S.; Bryant, S.; Lymp, J.F.; Bradwell, A.R.; Kyle, R.A. Serum reference intervals and diagnostic ranges for free $\mathrm{K}$ and free $\lambda$ immunoglobulin light chains: Relative sensitivity for detection of monoclonal light chains. Clin. Chem. 2002, 48, 1437-1444. [CrossRef]

44. Geary, W.; Frierson, H.; Innes, D.; Normansell, D. Quantitative criteria for clonality in the diagnosis of B-cell non-Hodgkin's lymphoma by flow cytometry. Mod. Pathol. 1993, 6, 155-161.

45. Criado, I.; Rodríguez-Caballero, A.; Gutiérrez, M.L.; Pedreira, C.E.; Alcoceba, M.; Nieto, W.; Teodosio, C.; Bárcena, P.; Romero, A.; Fernández-Navarro, P.; et al. Low-count monoclonal B-cell lymphocytosis persists after seven years of follow up and is associated with a poorer outcome. Haematologica 2018, 103, 1198-1208. [CrossRef]

46. Miron, M.; Meng, W.; Rosenfeld, A.M.; Dvorkin, S.; Meimei, M.; Poon, L.; Lam, N.; Kumar, B.V.; Louzoun, Y.; Prak, E.T.L.; et al. Maintenance of the human memory T cell repertoire by subset and tissue site. Genome Med. 2021, 13, 100. [CrossRef] [PubMed]

47. Flores-Montero, J.; Sanoja-Flores, L.; Paiva, B.; Puig, N.; García-Sánchez, O.; Böttcher, S.; Van Der Velden, V.H.J.; Pérez-Morán, J.J.; Vidriales, M.B.; García-Sanz, R.; et al. Next Generation Flow for highly sensitive and standardized detection of minimal residual disease in multiple myeloma. Leukemia 2017, 31, 2094-2103. [CrossRef] [PubMed]

48. Davidson, B.; Risberg, B.; Berner, A.; Smeland, E.B.; Torlakovic, E. Evaluation of lymphoid cell populations in cytology specimens using flow cytometry and polymerase chain reaction. Diagn. Mol. Pathol. 1999, 8, 183-188. [CrossRef] [PubMed] 